\title{
EcoDes-DK15: high-resolution ecological descriptors of vegetation and terrain derived from Denmark's national airborne laser scanning data set
}

\author{
Jakob J. Assmann ${ }^{1}$, Jesper E. Moeslund ${ }^{2}$, Urs A. Treier ${ }^{1,3}$, and Signe Normand ${ }^{1,3}$ \\ ${ }^{1}$ Ecoinformatics and Biodiversity, Department of Biology, Aarhus University, Aarhus, 8000, Denmark \\ ${ }^{2}$ Biodiversity, Department of Ecoscience, Aarhus University, Rønde, 8410, Denmark \\ ${ }^{3}$ Center for Sustainable Landscapes Under Global Change, Department of Biology \\ Aarhus University, Aarhus, 8000, Denmark \\ Correspondence: Jakob J. Assmann (j.assmann@bio.au.dk)
}

Received: 29 June 2021 - Discussion started: 14 July 2021

Revised: 5 January 2022 - Accepted: 8 January 2022 - Published: 23 February 2022

\begin{abstract}
Biodiversity studies could strongly benefit from three-dimensional data on ecosystem structure derived from contemporary remote sensing technologies, such as light detection and ranging (lidar). Despite the increasing availability of such data at regional and national scales, the average ecologist has been limited in accessing them due to high requirements on computing power and remote sensing knowledge. We processed Denmark's publicly available national airborne laser scanning (ALS) data set acquired in 2014/15, together with the accompanying elevation model, to compute 70 rasterised descriptors of interest for ecological studies. With a grain size of $10 \mathrm{~m}$, these data products provide a snapshot of high-resolution measures including vegetation height, structure and density, as well as topographic descriptors including elevation, aspect, slope and wetness across more than $40000 \mathrm{~km}^{2}$ covering almost all of Denmark's terrestrial surface. The resulting data set is comparatively small ( $\sim 94 \mathrm{~GB}$, compressed $16.8 \mathrm{~GB})$, and the raster data can be readily integrated into analytical workflows in software familiar to many ecologists (GIS software, R, Python). Source code and documentation for the processing workflow are openly available via a code repository, allowing for transfer to other ALS data sets, as well as modification or re-calculation of future instances of Denmark's national ALS data set. We hope that our high-resolution ecological vegetation and terrain descriptors (EcoDes-DK15) will serve as an inspiration for the publication of further such data sets covering other countries and regions and that our rasterised data set will provide a baseline of the ecosystem structure for current and future studies of biodiversity, within Denmark and beyond. The full data set is available on Zenodo: https://doi.org/10.5281/zenodo.4756556 (Assmann et al., 2021); a 5 MB teaser subset is also available: https://doi.org/10.5281/zenodo.6035188 (Assmann et al., 2022a).
\end{abstract}

\section{Introduction}

Over the last decades, airborne laser scanning (ALS) has become an established data source for providing fine-resolution measures of terrain and vegetation structure in ecological research (Moeslund et al., 2019; Guo et al., 2017; Zellweger et al., 2016). Despite its informative potential and the increasing number of openly available ALS data sets with regional and national extents (Vo et al., 2016), the uptake of these data sets for large-scale ecological research and applications (such as monitoring and conservation) has remained comparatively low (Bakx et al., 2019). The low uptake is likely a consequence of the considerable challenges that remain in handling these very large data sets, which require specialist expertise and software, as well as substantial amounts of data storage and processing power (Meijer et al., 2020; Vo et al., 2016; Pfeifer et al., 2014). Here, we address this issue for Denmark by providing a compact set of ecologically relevant measures of terrain characteristics and vegetation structure 
derived as raster outputs from the country's national ALS data set with a grain size of $10 \mathrm{~m} \times 10 \mathrm{~m}$.

The typical output from an ALS survey is a so-called point cloud that describes the physical structure of the surveyed area in three-dimensional space (Bakx et al., 2019; Vierling et al., 2008). In brief, short laser pulses are sent out from a light detection and ranging (lidar) sensor mounted on an aeroplane (or drone) and reflected by surfaces such as bare ground, plants or buildings. The return timing of the reflected signal is measured and - with the help of information on the sensor's orientation and position - the precise location of the reflecting surface is determined in geographic space (Vierling et al., 2008). If an object intercepting the light pulse is smaller than the beam's footprint (e.g. a leaf or a branch of a tree), some of the light may travel on and trigger a reflection from a second surface (e.g. understorey vegetation or the forest floor). A single light pulse might therefore generate two or even more returns, allowing - to some degree - for the penetration of forest canopies (Ackermann, 1999). Often, the raw signal is processed by the survey provider, and the resulting data are delivered to the end user in the form of a point cloud of discrete returns, in which each point is associated with information on geographic location, return strength (amplitude), return number, acquisition timing, etc. (Vo et al., 2016). For ALS data sets with large extents - such as Denmark's nationwide data set "DHM/Punktsky" - outputs from many survey flights are co-registered and merged, resulting in very large point clouds with hundreds of billions of points and data volumes of multiple terabytes (Geodatastyrelsen, 2015). For further information on ALS data acquisition, we recommend Vo et al. (2016), Vierling et al. (2008), and Wagner et al. (2006).

Based on point position and neighbourhood context it is possible to separate ground and vegetation returns in ALS point clouds, allowing for the calculation of descriptors of terrain and vegetation structure. Filtering bare ground from the point cloud may be achieved with algorithms (Moudrý et al., 2020; Sithole and Vosselman, 2004), while more complex segmentation of the point clouds into object classes (such as vegetation, buildings, etc.) is done manually or with the help of supervised machine learning (see Lin et al., 2020, for a recent overview). Early applications for ALS were focussed on generating simple digital elevation models (DEMs), city and landscape planning, and forestry (Ackermann, 1999), but over the last decades applications have expanded into other fields, including, amongst others, the calculation of terrain and vegetation measures for ecological research. Terrainderived measures of ecological interest include topographic slope, aspect (i.e. slope direction), solar irradiation, wetness, etc. (e.g. Moeslund et al., 2019; Zellweger et al., 2016; Ceballos et al., 2015), and vegetation structural descriptors include vegetation density, canopy height diversity, canopy roughness and many more (e.g. Bakx et al., 2019; Moeslund et al., 2019; Coops et al., 2016). It is important to note that point cloud characteristics may limit the type of measures that can be meaningfully derived from ALS data (Bakx et al., 2019). This applies especially to the point cloud density, which needs to be high enough to meaningfully resolve the structure of understorey layers in forests (Bakx et al., 2019) or ecosystems with vegetation of low stature such as grasslands or tundra (Boelman et al., 2016). Nonetheless, even simpler ALS-derived descriptors of terrain and vegetation structure can be of high value for ecological applications, as fieldwork-derived alternatives are often too costly and difficult to collect over large extents (Vierling et al., 2008).

ALS data have provided critical information for research on biodiversity and habitat characteristics over recent years, and their importance in ecological research is likely to increase in the future. Numerous biodiversity studies have successfully deployed ALS to study organisms like plants (Mao et al., 2018; Lopatin et al., 2016; Zellweger et al., 2016; Ceballos et al., 2015; Moeslund et al., 2013; Leutner et al., 2012), fungi (Peura et al., 2016; Thers et al., 2017), bryophytes, lichens (Moeslund et al., 2019), mammals (Tweedy et al., 2019; Froidevaux et al., 2016) and birds (see Bakx et al., 2019, for a comprehensive review) both in open landscapes and in forests. These studies have all emphasised the value of ALS for representing fine-scale ( $\sim 10 \mathrm{~m}$ resolution) terrain or vegetation structural variation important to local biodiversity patterns. Furthermore, Valbuena et al. (2020) recently considered ALS data to be one of the key resources for deriving ecosystem morphological traits in the global assessment of essential biodiversity variables (EBVs). Finding ways of making regional and nationwide ALS data more accessible to the average ecologist is therefore not only a critical priority for accelerating research on regional biodiversity patterns and species-habitat relationships but also for the facilitation of global assessments such as those carried out by IPBES (2019) and others alike.

To open up opportunities for researchers and practitioners not familiar with ALS processing or without access to the required facilities, we present a new national ALS-based data set for Denmark primarily aimed at ecological research with possible uses in other disciplines. With a grain size of $10 \mathrm{~m}$, these ecological descriptor (EcoDes) rasters provide a snapshot of high-resolution measures of vegetation height, structure and density, as well as topographic descriptors including elevation, aspect, slope and wetness, for almost all of Denmark's terrestrial surface between spring 2014 and summer 2015 (DK15). In this publication, we (a) describe the source data and outline the processing workflow (Sect. 2.1-2.3), (b) summarise the data set's main characteristics (Sect. 3.1-3.2), (c) describe each descriptor in detail and highlight its use and limitations (Sect. 3.3-3.4), and (d) provide guidance on data access and illustrate how the data could be used in an example of ecological landscape classification (Sect. 4). We finish by (e) briefly discussing the general limitations of the data set and processing workflow, as well as providing perspectives on how the presented data can be complemented with other data sources (Sect. 5). 
We hope that ease of access and thorough documentation of the EcoDes-DK15 data set will encourage uptake and facilitate the development of future versions of similar data sets in Denmark and beyond.

\section{Source data and processing workflow overview}

\subsection{Denmark - geography and ecology}

Located in northern Europe, Denmark (without Greenland and the Faroe Islands) has an approximate land area of $43000 \mathrm{~km}^{2}$, comprising the large peninsula of Jutland and 443 named islands. The relatively flat (highest point is $171 \mathrm{~m}$ above sea level) landscape predominantly consists of arable land and production forest with relatively small patches of natural or semi-natural areas such as heathlands, grasslands, fresh and salt meadows, bogs, dunes, lakes, streams, and deciduous forests.

\subsection{ALS and elevation source data}

The Danish elevation model (DHM) is an openly available nationwide data set providing various products based on ALS data. Here, we used the DHM/Point-cloud (DHM/Punktsky), the classified georeferenced ALS point cloud product, and the DHM/Terrain (DHM/Terræn), the digital elevation model product derived from the point cloud. The DHM data set is currently maintained by the Agency for Data Supply and Efficiency, Denmark (https://sdfe.dk/, last access: 13 October 2021), and, at the time of writing, it can be downloaded from https://kortforsyningen.dk/ (last access: 24 April 2020, continuously updated with new survey data) and https:// datafordeler.dk/ (last access: 13 October 2021, versioned). While almost all of Denmark's terrestrial surface was covered by ALS surveys in 2014/15, currently none of the products provided by the agency contain data exclusively from these surveys. We therefore merged three different versions of the source data to obtain a data set that reflects the state of the vegetation in $2014 / 15$ as best as possible by only containing vegetation data from 2014/15 and limited amounts from 2013 (Table 1, Sect. 3.6.3; see GitHub code repository for a detailed description of the merger and more information on the source data sets). The DHM/Point-cloud product is a collection of $1 \mathrm{~km} \times 1 \mathrm{~km}$ tiles of three-dimensional point clouds with attributes such as position, intensity, point source ID and classification. Point classification follows the ASPRS LAS 1.3 standard (ASPRS, 2011), including, for example, ground, vegetation and buildings. The point density is on average four to five points per square metre with a horizontal and vertical accuracy of 0.15 and $0.05 \mathrm{~m}$, respectively. Additional information on the data sets can be found in Geodatastyrelsen (Geodatastyrelsen, 2015 - in Danish), Thers et al. (2017), Nord-Larsen et al. (2017), and in the quality assessment report by Flatman et al. (2016). The DHM/Point-cloud product is provided in LAZ format and in the compound coordinate system for Denmark (ETRS89/UTM zone 32N + DVR90 height - EPSG:7416). The DHM/Terrain product is a rasterised digital model of the terrain height above sea level in $0.4 \mathrm{~m}$ resolution. This product is provided in a 32 bit GeoTIFF format, using the same $1 \mathrm{~km} \times 1 \mathrm{~km}$ tiling convention and spatial reference system as the DHM/Point-cloud.

The $1 \mathrm{~km} \times 1 \mathrm{~km}$ tiling of the DHM/Terrain 2014/15 and DHM/Point-cloud 2014/15 data sets matches in extent and geolocation. However, a small number of tiles $(n=30)$ in the DHM/Point-cloud data sets did not have corresponding tiles in the DHM/Terrain data sets; these were removed prior to processing, resulting in the total of 49673 tiles shown in Table 1.

\subsection{Processing}

We processed the source data using OPALS 2.3.2.0 (Pfeifer et al., 2014), Python 2.7 (Van Rossum and Drake, 1995), pandas 0.24.2 (Reback et al., 2019), SAGA GIS 7.8.2 (Conrad et al., 2015), and GDAL 2.2.4 (GDAL/OGR contributors, 2018) from OSgeo4W64. Some re-processing was required during the peer review process, for which we used GDAL 3.3.3 from Osgeo4W64 (GDAL/OGR contributors, 2022). The large number of tiles and descriptors to be calculated required us to develop a robust processing pipeline, which we realised as a set of Python modules. The source code is openly available via a GitHub code repository (see Sect. 6). Processing was carried out on a Dell PowerEdge R740xd computational server (Windows 2012 R2 64 bit operating system, $2 \times$ Intel Xeon Platinum 8180 processors and 1.536 TB RAM). The processing of the whole data set took approximately $45 \mathrm{~d}$ to complete.

\section{Processing workflow}

To facilitate the processing of the large data set, we first generated a set of compact Python modules providing a programming interface that allows for the calculation of the individual descriptors outlined in Sect. 3. The individual routines were then integrated into a Python script mediating the processing workflow in parallel while carrying out error handling, logging and progress tracking. The schematic of the processing workflow and the Python modules is outlined in Fig. 1. Detailed information is available on the GitHub repository, including instructions on how to set up the processing, documentation on the functions provided by the Python modules and detailed in-text commentary of the code.

We generated the processing workflow so that it should be possible to adapt it to other point cloud data sets. However, the effort required in achieving this will vary depending on various features of the point cloud data set in question (such as tiling and tile naming conventions, input/output grain sizes, etc.). A key pre-requisite is that the point cloud is pre-classified, ideally following the ASPRS LAS 1.1-1.4 standards (ASPRS, 2019). We have also provided a helper 
Table 1. Overview of the data sources used for generating the EcoDes-DK15 data set. Three versions of the DHM/Point-cloud were merged to obtain a point cloud data set that contained no vegetation points scanned after 2015 and as little vegetation points before 2014 as possible. DHM/Terrain tiles were matched sources from the same data source as the corresponding point cloud tiles. A copy of the source data is archived on the internal long-term data storage at Aarhus University and is available on request. For further information see documentation on GitHub code repository and Sect. 3.6.3.

\begin{tabular}{|c|c|c|c|c|c|}
\hline Data source & Years & Used for & Data provider & $\begin{array}{l}\text { Downloaded available } \\
\text { from (download date) }\end{array}$ & Number of tiles \\
\hline $\begin{array}{l}\text { DHM/Point-cloud } \\
\text { (DHM/Punktsky) }\end{array}$ & $2007-2018$ & Vegetation descriptors & $\begin{array}{l}\text { Danish Agency } \\
\text { for Data Supply } \\
\text { and Efficiency }\end{array}$ & $\begin{array}{l}\text { https://kortforsyningen. } \\
\text { dk/ (24 April 2020) }\end{array}$ & 38671 \\
\hline $\begin{array}{l}\text { DHM/Point-cloud } \\
\text { (DHM2015_punktsky) }\end{array}$ & $2007-2018$ & Vegetation descriptors & $\begin{array}{l}\text { Danish Agency } \\
\text { for Data Supply } \\
\text { and Efficiency }\end{array}$ & $\begin{array}{l}\text { https://datafordeler.dk } \\
(13 \text { October 2021) }\end{array}$ & 10955 \\
\hline $\begin{array}{l}\text { DHM/Point-cloud } \\
\text { (GST_2014) }\end{array}$ & $2007-2015$ & Vegetation descriptors & $\begin{array}{l}\text { Danish Agency } \\
\text { for Data Supply } \\
\text { and Efficiency }\end{array}$ & $\begin{array}{l}\text { https://kortforsyningen. } \\
\mathrm{dk} / \text { (unknown, } \\
\text { before 2017) }\end{array}$ & 47 \\
\hline $\begin{array}{l}\text { DHM/Terrain } \\
\text { (DHM/Terræn) }\end{array}$ & $2007-2018$ & Terrain descriptors & $\begin{array}{l}\text { Danish Agency } \\
\text { for Data Supply } \\
\text { and Efficiency }\end{array}$ & $\begin{array}{l}\text { https://kortforsyningen. } \\
\text { dk/ (24 April 2020) }\end{array}$ & 38671 \\
\hline $\begin{array}{l}\text { DHM/Terrain } \\
\text { (DHM2015_terraen) }\end{array}$ & 2007-2018 & Terrain descriptors & $\begin{array}{l}\text { Danish Agency } \\
\text { for Data Supply } \\
\text { and Efficiency }\end{array}$ & $\begin{array}{l}\text { https://datafordeler.dk } \\
(13 \text { October 2021) }\end{array}$ & 10955 \\
\hline $\begin{array}{l}\text { DHM/Terrain } \\
\text { (GST_2014) }\end{array}$ & $2007-2015$ & Terrain descriptors & $\begin{array}{l}\text { Danish Agency } \\
\text { for Data Supply } \\
\text { and Efficiency }\end{array}$ & $\begin{array}{l}\text { https://kortforsyningen. } \\
\mathrm{dk} / \text { (unknown, } \\
\text { before 2017) }\end{array}$ & 47 \\
\hline
\end{tabular}

script that can be adapted to generate a raster digital terrain model (DTM) from the point cloud should this not be available; see the documentation on the GitHub repository for the details. Finally, the modular nature of the processing workflow allows for only a subset of the output descriptors to be calculated and the integration of additional processing routines for any new user-defined descriptors.

\section{Data set description and known limitations}

\subsection{Extent, projection, resolution and data format}

EcoDes-DK15 covers the majority of Denmark's land area, including the island of Bornholm (approximate extent: 54.56 to $57.75^{\circ} \mathrm{N}, 8.07$ to $15.20^{\circ} \mathrm{E}$ ). The data are projected in ETRS89 UTM 32N based on the GRS80 spheroid (EPSG: 25832). The data set is available as GeoTIFFs with $10 \mathrm{~m}$ grain size via a data repository on Zenodo (see Sect. 6). For each descriptor the nationwide data are split into 49673 raster tiles of $1 \mathrm{~km} \times 1 \mathrm{~km}$ with a $10 \mathrm{~m}$ grain size based on 25 -fold aggregations of the $0.4 \mathrm{~m}$ national grid of Denmark. A virtual raster mosaic (VRT) file is provided for each descriptor (except the point_source_counts, point_source_ids and point_source_proportion descriptors), and a file containing the tile footprint geometries can be used for geographical subsetting of the data. We also provide masks for inland water and the sea.

The final data set consists of just under $94 \mathrm{~GB}$ of data (compressed for download $16.8 \mathrm{~GB}$ ). To reduce the size of the data set we converted numerical values from floating point precision to 16 bit integers where possible. In some cases, this required us to stretch the values by a set factor to maintain information content beyond the decimal point. The descriptor conversion factors are available as a csv file provided with the data set and in Table 2. Missing data (NoData) is denoted by a value of -9999 throughout the data set.

\subsection{Overview and file naming convention}

An overview of the 18 terrain and vegetation structure descriptors, as well as the auxiliary data provided, can be found in Table 2. Generally, the descriptor names in Table 2 reflect the prefix of the file name of a GeoTIFF file within the data set. This prefix is followed by a suffix representing the unique identifier for each tile based on the UTM coordinates of the tile (see Sect. 3.4.3 for more detail). When working with the complete data set, tiles from the same descriptor are grouped within a folder using the same descriptor name as used for the file name prefix. For example, for the tile with the unique id "6239_446" the GeoTIFF for the "dtm_10m" descriptor can 


\section{Processing Workflow Overview}

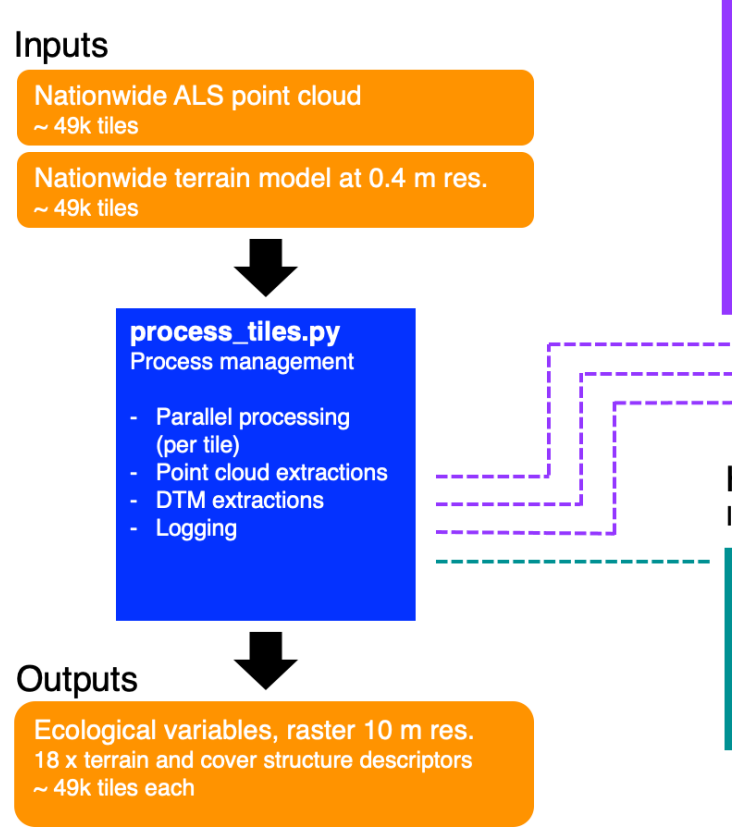

dk_lidar

Python Modules

points.py Point cloud handling and extraction functions

Point cloud ingestion Footprint extraction

Descriptor

extractions

OPALS bindings in

Python.
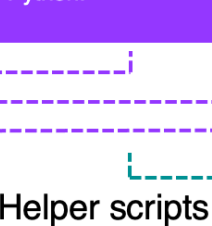

Independent python scripts

progress_monitor.py Process monitoring

Displays progress Estimates time remaining
DTM handling and

extraction functions

Footprint extraction

- Aggregations

Descriptor

extractions

GDAL and SAGA GIS

binaries.
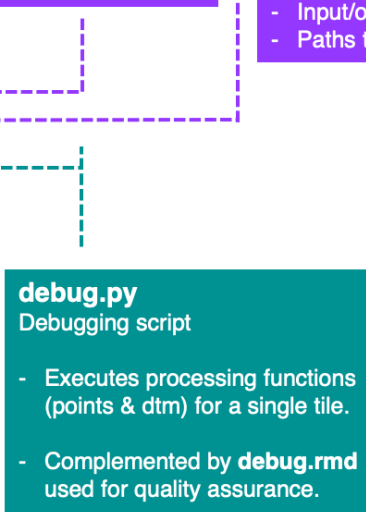

Figure 1. Diagram of the processing workflow, the $d k \_l i d a r$ Python module and helper scripts. The workflow requires two inputs: a preclassified set of point cloud tiles and a paired set of digital terrain model (DTM) tiles. The process management is handled by the process_tiles.py script which facilitates processing of each tile pair (DTM and point cloud) in parallel and logs the progress. For each tile, process_tiles.py calls a specified set of extraction and processing functions from the $d k \_l i d a r$ modules. Point cloud extraction functions are specified in points.py and terrain model extraction functions are specified in $d t m . p y$. The dk_lidar modules also contain two further files: common.py, a script containing specifications of common functions used by the points.py and dtm.py,, as well as settings.py, which is used to set global processing options, specify file paths, etc. Finally, two helper scripts are provided: progress_monitor.py, which facilitates progress monitoring and estimates the time remaining, and debug.py, a script for testing the workflow for a single tile. Together the Python scripts and modules allow the ecological descriptor outputs from the two input data sets to be generated. Further documentation of the $d k \_l i d a r$ modules and workflow scripts can be found on the GitHub repository associated with this publication: https://github.com/jakobjassmann/ecodes-dk-lidar (last access: 5 January 2022).

be found in "dtm_10m/dtm_10m_6239_446.tif". The exceptions are the point counts, vegetation proportions and point source information; please see the relevant sections below for more detail.

\subsection{Completeness of the data set}

The processing of the data set was almost completely successful. Processing failed on average for only 18 out of the 49673 tiles per descriptor with a maximum of 65 tiles failing for the canoy_height, normalized_z_mean and normal$i z e d \_z \_s d$ descriptors. The majority of these tiles were located on the fringes of the data set, including sand spits, sandbanks etc. We therefore did not attempt to re-process those tiles. Instead, we generated NoData rasters for all missing descriptor-tile combinations (i.e. we assigned -9999 to all cells in those tiles). We provide a text file listing the affected "NoData" tiles in the folder of each descriptor (the file is named empty_tiles_XXX.txt, where XXX is the descriptor name).

\subsection{Elevation-model-derived descriptors}

The following descriptors were solely derived from the $0.4 \mathrm{~m}$ digital elevation model (DHM/Terrain). Visualisations of these descriptors for an example tile in the Mols Bjerge area are shown in Fig. 2.

\subsubsection{Elevation (dtm_10m)}

We aggregated the $0.4 \mathrm{~m}$ DEM by mean to match the $10 \mathrm{~m} \times$ $10 \mathrm{~m}$ national grid of the remainder of the data set. We used gdalwarp to carry out the aggregations. Values represent the elevation above sea level in metres (DVR90, EPSG: 5799) multiplied by a factor of 100 , rounded to the nearest integer and converted to 16 bit integer. 
Table 2. Brief overview of the 18 main EcoDes-DK15 descriptors and descriptor groups, their ecological meaning, unit, format and conversion factor. See Sect. 3.4 for a detailed description of each descriptor. In addition to the 70 raster layers for the main descriptors, the data set contains 9 layers of auxiliary information (see Sect. 3.7). Note: to obtain the correct unit, the descriptor value needs to be divided by the conversion factor.

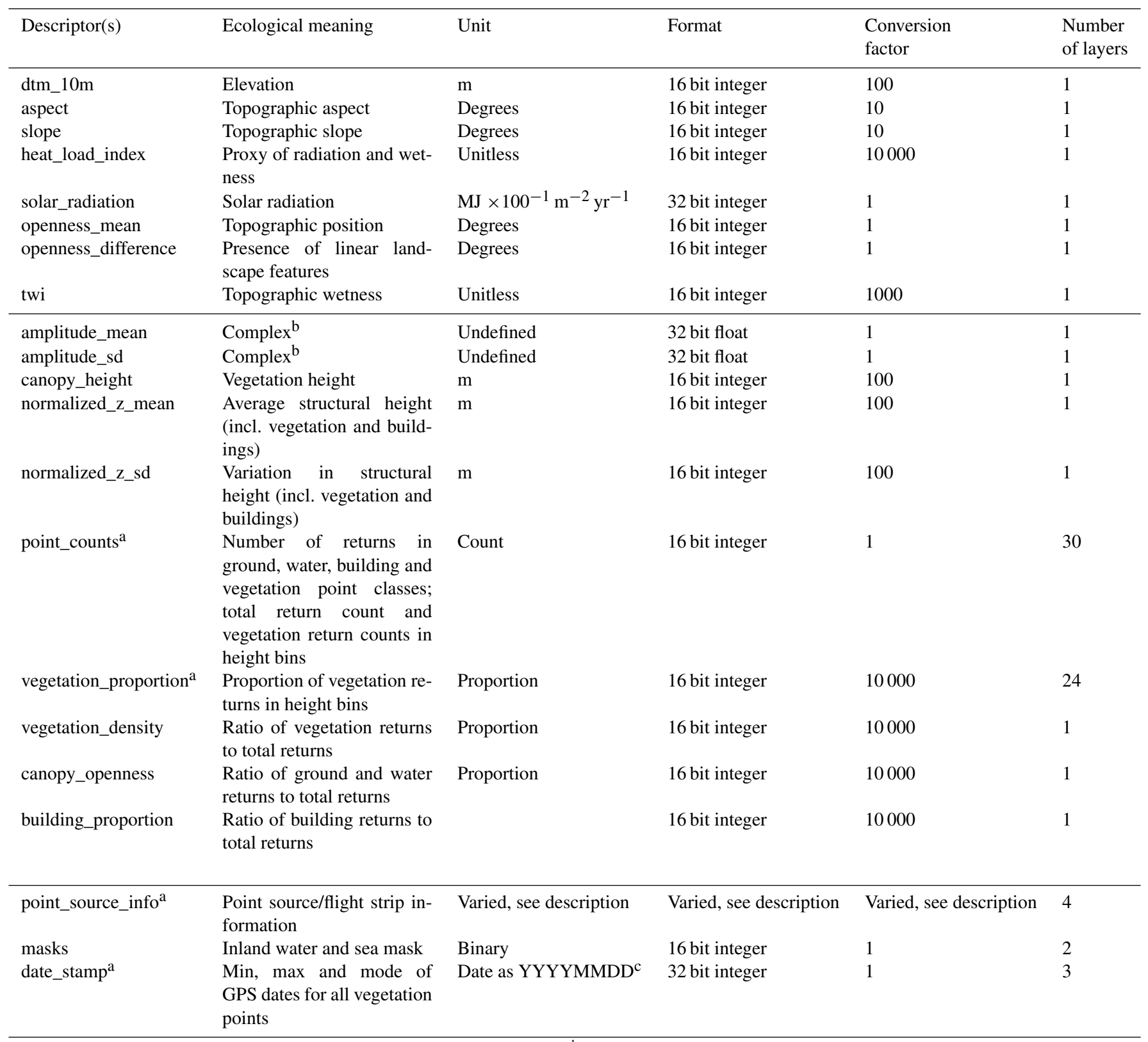

${ }^{a}$ Descriptor group containing multiple individual descriptors; see in-text description for detail. ${ }^{\mathrm{b}}$ The amplitude descriptors are difficult to interpret but can serve as useful indicators for vegetation classification and biodiversity studies. Please see in-text description for more detail. ${ }^{\mathrm{c}}$ YYYY $=$ year in four digits, $\mathrm{MM}=$ month in two digits, DD $=$ day in two digits.

\subsubsection{Aspect (aspect)}

The topographic aspect describes the orientation of a slope in the terrain and may, amongst other things, be related to plant growth through light and moisture availability. We calculated the aspect in degrees, with $0^{\circ}$ indicating north, $90^{\circ}$ east, $180^{\circ}$ south and $270^{\circ}$ west. Values represent the aspect derived from a $10 \mathrm{~m}$ aggregate of the elevation model (aggregated by mean with 32 bit floating point precision). Calculations were carried out using gdaldem binaries and the "aspect" option, which by default uses Horn's method to calculate the aspect (Horn, 1981). To avoid edge effects, all calculations were done on a mosaic that included the focal tile and all available directly neighbouring tiles (maximum eight). The mosaic was cropped back to the extent of the focal tile upon completion of the calculations. We then converted the value for each cell from radians to degrees, multiplied it by a factor 
(a) orthophoto

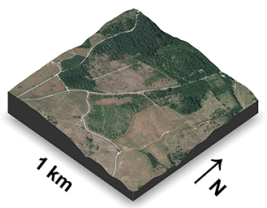

(d) slope

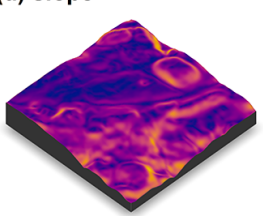

(g) openness_mean

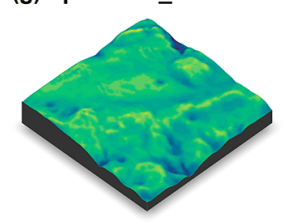

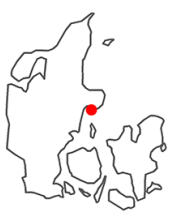

(b) dtm_10m
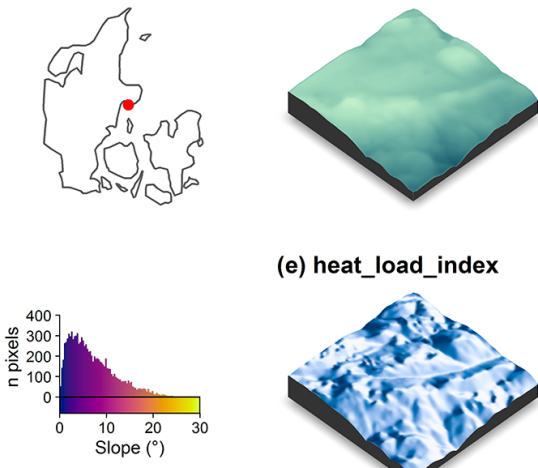

(h) openness_difference

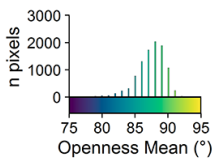

(e) heat_load_index
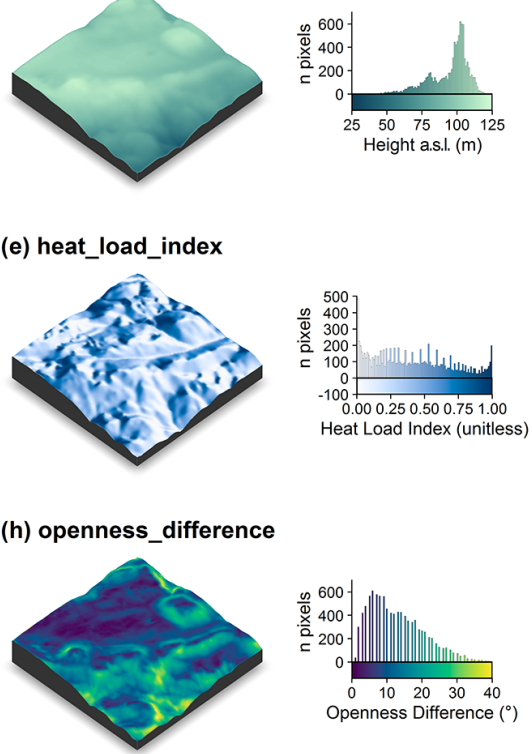

Heat Load Index (unitless) (c) aspect
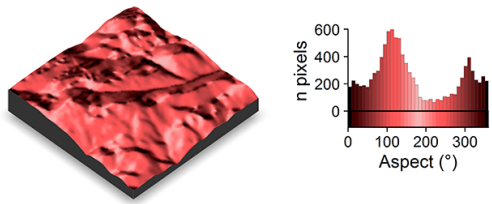

(f) solar_radiation
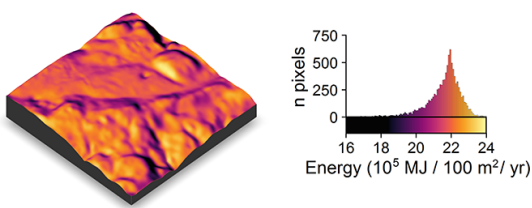

(i) twi
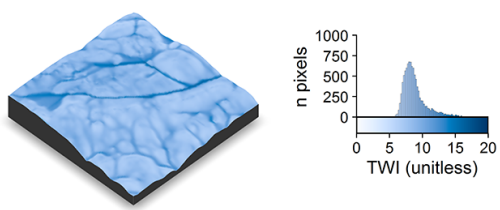

Figure 2. Illustration of the terrain-model-derived descriptors for a $1 \mathrm{~km} \times 1 \mathrm{~km}$ tile in the Mols Bjerge area (tile id: 6230_595). An orthophoto and the tile location relative to Denmark are shown in (a). The terrain model (dtm_10m) is illustrated in (b). The terrain-derived descriptors are comprised of (c) the topographic aspect, (d) the topographic slope, (e) the heat load index following McCune and Keon (2002), (f) the estimated incident solar radiation, (g) the landscape openness mean, (h) the landscape openness difference in the eight cardinal directions and (i) the topographic wetness index (TWI) based on Kopecký et al. (2020). For visualisation purposes, we amplified the altitude above sea level by a factor of 2 in the three-dimensional visualisations and divided the solar radiation values by $10^{5}$. The three-dimensional raster visualisations were generated using the rayshader v0.19.2 package in R (Morgan-Wall, 2020). Orthophoto provided by the Danish Agency for Data Supply and Efficiency (https://sdfe.dk/hent-data/fotos-og-geodanmark-data/, last access: 28 June 2021).

of 10 , rounded to the nearest integer and stored the results as a 16 bit integer. Finally, we assigned a value of $-10\left(-1^{\circ}\right)$ to all cells where the slope was $0^{\circ}$ (flat). Limitations in the aspect arise in relation to edge effects that occur where a neighbourhood mosaic is incomplete for a focal tile (i.e. less than eight neighbouring tiles), such as for tiles along the coastline or at the edge of the covered extent. For those tiles, no aspect can be derived for the rows or columns at the edge of the mosaic. The cells in those rows and columns have no neighbouring cells and were assigned the NoData value (-9999). Please also note that we calculated the aspect descriptor from the $10 \mathrm{~m}$ aggregate of the DTM/Terrain data set rather than deriving it from the $0.4 \mathrm{~m}$ original-resolution rasters and then aggregating it. The latter approach could represent the aspect at the original resolution better (Grohmann, 2015; Moudrý et al., 2019), but would create inconsistencies within how the remaining DTM/Terrain descriptors are calculated in this data set.

\subsubsection{Slope (slope)}

The topographic slope describes the steepness of the terrain and amongst other things may be related to moisture availability, exposure and erosion. We derived the topographic slope in degrees with a $10 \mathrm{~m}$ grain size from a mean ag- gregate of the elevation model ( 32 bit floating point precision) using the gdaldem binaries with the "slope" option, which by default use Horn's method to calculate the slope (Horn, 1981). To avoid edge effects, we carried out the calculations on a mosaic including the focal tile and all available directly neighbouring tiles (maximum eight). The mosaic was cropped back to the extent of the focal tile upon completion of the calculations. The value for each cell was converted from radians to degrees, multiplied by a factor of 10 , rounded to the nearest integer and stored as a 16 bit integer. Limitations in the slope arise in relation to edge effects that occur where a neighbourhood mosaic is incomplete for a focal tile (i.e. less than eight neighbouring tiles), such as for tiles along the coastline or at the edge of the covered extent. For those tiles, no slope can be derived for the rows or columns at the edge of the mosaic. These cells in those rows and columns have no neighbouring cells, and gdaldem assigns the NoData value (-9999) to these cells. Please also note that we calculated the slope descriptor from the $10 \mathrm{~m}$ aggregate of the DTM/Terrain data set rather than deriving it from the $0.4 \mathrm{~m}$ original-resolution rasters and then aggregating it. The latter approach could represent the slope at the original resolution better (Grohmann, 2015; Moudrý et al., 2019), but would create inconsistencies within how the re- 
maining DTM/Terrain descriptors are calculated in this data set.

\subsubsection{Landscape openness mean (openness_mean)}

Landscape openness is a landform descriptor that indicates whether a cell is located in a depression or elevation of the landscape. We calculate the landscape openness following Yokoyama (2002) using the OPALS implemented algorithms. We used a mean aggregate of the elevation model with $10 \mathrm{~m}$ grain size and 32 bit floating point precision and derived the mean landscape openness for a cell as the mean of the landscape openness in all eight cardinal directions with a search radius of $150 \mathrm{~m}$. We chose to base this descriptor on the aggregated $10 \mathrm{~m}$ elevation model and a $150 \mathrm{~m}$ search radius as we think that these are best suited to describe the landscape-scale variation in the landforms of Denmark. Danish landscapes are characterised by gently undulating terrain, valleys forged by small to medium sized rivers and dune systems along the coastlines. First, we generated a mosaic including the focal tile and all available tiles in the direct neighbourhood (max. eight neighbouring tiles) to reduce edge effects in subsequent calculations. The mean of the positive openness for all eight cardinal directions with search radius of $150 \mathrm{~m}$ was then derived for all cells in the mosaic using the OPALS Openness module (options: feature = "positive", kernelSize $=15$ and selMode $=0$ ). Next, the mean openness per cell was converted from radians to degrees, rounded to the nearest integer and stored as a 16 bit integer. For incomplete neighbourhood mosaics (i.e. containing less than eight neighbouring tiles) we then masked out cells within the first $150 \mathrm{~m}$ of all edges where a neighbourhood tile was missing. Finally, the output was cropped back to the extent of the focal tile. As a consequence of the edge-effect-related masking, the focal tiles on the fringes of the data set, such as those on coastlines or at the edge of the coverage area, have no data available for the first $150 \mathrm{~m}$. The corresponding cells for the affected areas are set to the NoData value -9999 .

\subsubsection{Landscape openness difference (openness_difference)}

In addition to the mean of the landscape openness, we also derived a landscape openness difference measure. This difference measure is an indicator of whether a cell is part of a linear feature in the landscape that runs in one cardinal direction, such as a ridge or valley, therefore providing additional information to the landscape openness_mean descriptor. We calculated the landscape openness difference based on the $10 \mathrm{~m}$ mean aggregate of the elevation model (32 bit floating point precision) and with a search radius of $50 \mathrm{~m}$. We chose these parameters as we consider them best suited to capture the relatively narrow valleys and ridgetops common in the Danish landscape. First, we generated a mosaic including the focal tile and all available tiles in the direct neighbour- hood (max. eight neighbouring tiles) to reduce edge effects in subsequent calculations. We then calculated the minimum and maximum of the positive landscape openness from all eight cardinal directions for all cells in the mosaic using the OPALS Openness module with a search radius of $50 \mathrm{~m}$ (feature $=$ "positive", kernelSize $=5$, selMode $=1$ for minimum and selMode $=2$ for maximum). Next, we converted the minimum and maximum values from radians to degrees and calculated the difference between the maximum and minimum value. We rounded the result to the nearest full degree. For the cases where the neighbourhood mosaic was incomplete, i.e. containing less than eight neighbouring tiles, we masked out all cells within the first $50 \mathrm{~m}$ of all edges with a missing neighbourhood tile. The final output mosaic was then cropped to the extent of the focal tile and stored as a 16 bit integer GeoTIFF. As a consequence of the edge-effect-related masking, focal tiles on the edges of the data set, such as those on coastlines or at the edge of the coverage area, have no data available for the first $50 \mathrm{~m}$.

\subsubsection{Solar radiation (solar_radiation)}

Incident solar radiation is a key parameter for plant growth as it represents the electromagnetic energy available to plants required for photosynthesis. However, in the comparatively flat country of Denmark, shading by other vegetation likely exerts a larger influence on photosynthetic activity than terrain-related shading. Here, the impact of incident solar radiation on the local climate likely plays a more important role for determining plant growth due to its influence on drought and water dynamics (Moeslund et al., 2019). We estimated the amount of incident solar radiation received per cell $\left(100 \mathrm{~m}^{2}\right)$ per year from the slope and aspect computed as described above. Calculations were implemented using gdal_calc, following Eq. (3) specified in McCune and Keon (2002):

solar_radiation $=10^{6}$
$\times e^{0.339+0.808 \times \cos (L) \times \cos (S)-0.196 \times \sin (L) \times \sin (S)-0.482 \times \cos (180-|(180-A)|) \times \sin (S)}$,

where $L$ is the centre latitude of the cell in degrees, $S$ is the slope of the cell in degrees, and $A$ is the aspect of the cell in degrees. The resulting estimate is given in $\mathrm{MJ} \times 100^{-1} \mathrm{~m}^{-2} \mathrm{yr}^{-1}$ (McCune and Keon, 2002). Slope and aspect for each $10 \mathrm{~m} \times 10 \mathrm{~m}$ grid cell were sourced from the slope and aspect rasters. We saved the result as 32 bit integers. Due to propagation from the calculation of slope descriptor, no solar radiation values can be calculated for cells found right on the edge of the data set, for example in tiles situated along the coastline or at the edge of the sampling extent. 


\subsubsection{Heat load index (heat_load_index)}

The heat load index (McCune and Keon, 2002) was originally developed as an indicator for temperature based solely on aspect, but this characteristic is probably better captured in our solar radiation descriptor (see above) that was developed to improve shortcomings in the heat load index (McCune and Keon, 2002). However, in a previous study (Moeslund et al., 2019) we show that - in Denmark - the index was moderately correlated with soil moisture and can therefore serve as a useful indicator of the amount of moisture available to plants. We calculated the heat load index based on the aspect rasters (described above) following the equation specified in McCune and Keon (2002) using gdal_calc:

heat_load_index $=\frac{(1-\cos (A-45))}{2}$,

where $A$ is the aspect in degrees. We stretched the result by a factor of 10000 , rounded to the nearest integer and stored it as a 16 bit integer. As the heat_load_index is not meaningfully defined for flat cells (slope $=0^{\circ} /$ aspect $=-1^{\circ}$ ), we set the value of those cells to NoData (-9999). Finally, for cells that are located on the outermost edges of the data set the heat_load_index is not defined due to propagation of the NoData value assigned to the aspect in those cells.

\subsubsection{Topographic wetness index (TWI)}

The topographic wetness index (TWI) provides a proxy measure of soil moisture or wetness based on the hydrological flow modelled through a digital terrain model. Here, we derived the TWI following the method recommended by Kopecký et al. (2020). We based our calculations on the aggregated $10 \mathrm{~m}$ elevation model (dtm_10m, 16 bit integer) and used a neighbourhood mosaic (max. 8 neighbours) for each focal tile to derive the TWI. The exact procedure is detailed in the next paragraph. As such the index values calculated by us only consider a catchment the size of one tile and all its neighbours (for non-edge tiles this is a $3 \mathrm{~km} \times 3 \mathrm{~km}$ catchment, and for edge tiles it is smaller depending on the completeness of the neighbourhood mosaic). We then cropped the resulting output back to the extent of the focal tile, stretched the TWI values by a factor of 1000 , rounded to the next full integer and stored the results as a 16 bit integer.

We calculated the TWI using SAGA GIS v. 7.8.2 binaries. First, we sink-filled the neighbourhood mosaic of the terrain model using the ta_preprocessor 5 module and the option "MINSLOPE 0.01" (Wang and Liu, 2006). Second, we calculated the flow accumulation based on the sink-filled neighbourhood mosaic of the terrain model (from step one) using the ta_hydrology 0 module with options "METHOD 4" and "CONVERGENCE 1.0" (Freeman, 1991; Quinn et al., 1991). Third, we derived the flow width and specific catchment area based on the sink-filled neighbourhood mosaic of the terrain model (from step one) and the flow accumulation (from step two) using the module ta_hydrology
19 (Gruber and Peckahm, 2008; Quinn et al., 1991). Fourth, we calculated the slope based on the sink-filled neighbourhood mosaic of the terrain model (from step one) using the ta_morphometry 0 module with option "METHOD 7" (Haralick, 1983). Finally, we derived the TWI based on the specific catchment area (from step three) and slope (from step four) using the module ta_hydrology 20 (Beven and Kirkby, 1979; Böhner and Selige, 2006; Moore et al., 1991). For detailed descriptions of the modules used, please refer to the SAGA GIS documentation (SAGA-GIS Tool Library Documentation v7.8.2, 2021).

The TWI descriptor calculated for EcoDes-DK15 is subject to two main limitations: edge effects and small catchment size. Tiles with incomplete neighbourhoods (i.e. less than eight direct neighbours are available) will suffer from edge effects in the direct vicinity of the relevant border and overall due to a reduced catchment size. Furthermore, even in the ideal case of the neighbourhood being complete, for most cells flow accumulation is therefore only calculated for the direct neighbourhood of a focal tile, comprising a $3 \mathrm{~km} \times 3 \mathrm{~km}$ catchment area. While we hypothesise that, due to the relatively low variation in topography in Denmark, the TWI based on this comparably small catchment area will serve as a reasonable proxy for terrain-based wetness in most cases, it may be less reliable in areas with exceptionally high variation in topography or for lakes and rivers with large catchments. In addition, we would like to point the reader towards the general limitations of the TWI as a proxy for soil moisture or terrain wetness as, for example, discussed by Kopecký et al. (2020). These general limitations should be taken into account when interpreting the TWI values provided in EcoDes-DK15.

\subsection{Point-cloud-derived descriptors}

The DHM/Point-cloud point cloud was pre-classified into 11 point categories (Geodatastyrelsen, 2015) following the ASPRS LAS 1.3 standard (ASPRS, 2011). For the EcoDesDK15 data set, we restricted the analysis to six of these classes, including ground points ("Terræn") - class 2, water points ("Vand") - class 9, and building points ("Bygninger") - class 6, as well as low ("lav"), medium ("mellemhøj") and high vegetation ("høj vegetation") - classes 3,4 and 5, respectively. We grouped the three vegetation classes into one single vegetation class and, instead of the pre-assigned height categories, considered a more detailed set of height bins (see point-count and proportion descriptions below). The overall classification accuracy of the point cloud was assessed by the Danish authorities (Flatman et al., 2016), but limited information is available for the accuracy in each class. Thus, some degree of noise should be assumed across all classes. The tall vegetation category (class 6) was used as a catch-all class if classification failed, as often the case for very tall buildings and structures (Flatman et al., 2016). To reduce the noise related to such structures, we removed vegetation points with 
a normalised height exceeding $50 \mathrm{~m}$ above ground when calculating the vegetation point counts. We included all returns, i.e. first returns and echoes, in our analysis.

All point cloud processing was carried out using OPALS and the OPALS Python bindings. As none of the point-cloudderived descriptors required mosaicking to prevent edge effects, we processed all point cloud descriptors on the focal tile only. After the initial ingestion of the LAZ file for a tile into the OPALS data manager format (odm), we used the OpalsAddInfo module to add a normalised height ( $z$ ) attribute to the points. For this attribute we subtracted the height of the ground derived from the corresponding DHM/Terrain raster ( $0.4 \mathrm{~m}$ grid size) from the height above sea level of each point. Figure 3 illustrates how the point cloud data translates to some of the descriptor outputs for four exemplary $10 \mathrm{~m} \times 10 \mathrm{~m}$ cells from the data set, and an overview of the point-cloud-derived descriptors for a $1 \mathrm{~km} \times 1 \mathrm{~km}$ tile in Vejle Fjord in central Jutland is provided in Fig. 4.

\subsubsection{Amplitude - mean and standard deviation (amplitude_mean and amplitude_sd)}

The amplitude attribute of a point in the DHM/Point-cloud is the actual amplitude of the return echoes; i.e. it describes the strength of the lidar return signals detected by the sensor. The descriptor is difficult to interpret in terms of its ecological meaning. Nonetheless, we believe that it is still useful for vegetation classifications, biodiversity analysis and other applications that perform well with proxy data. We calculate the arithmetic mean and standard deviation of the amplitude for all points within a $10 \mathrm{~m} \times 10 \mathrm{~m}$ cell. Here, "all points" refers to all points classified as ground, water, building and vegetation points. Calculations were carried using the OPALS Cell module, and results were stored as 32 bit floats. The amplitude attributes in the DHM/Point-cloud point clouds are not directly comparable when points originate from different point sources (e.g. flight strips), as the amplitude has not been calibrated and hence is sensitive to differences in sensor, sensor configuration and signal processing. Calculating summary metrics such as mean and standard deviation for a $10 \mathrm{~m} \times 10 \mathrm{~m}$ cell where points from different point sources are present introduces additional complexities. In some cases, a $10 \mathrm{~m}$ cell might contain points from up to four different sources. We therefore recommend using the two amplitude descriptors with care and - if possible - in conjunction with information on the point source ids contained in the point_source_info descriptors described below.

\subsubsection{Canopy height (canopy_height)}

Canopy height is a key parameter of vegetation structure related to biomass and ecosystem functioning. We derived the canopy height in metres as the 95th percentile of the normalised height above ground of all vegetation points within each $10 \mathrm{~m} \times 10 \mathrm{~m}$ cell using the OPALS Cell module. The re- sulting canopy heights were multiplied by a factor of 100 , rounded to the nearest integer and stored as 16 bit integers. In cases where there were no vegetation points in any given cell, we set the canopy height value of the cell to $0 \mathrm{~m}$. Please note that the canopy height is therefore also set as $0 \mathrm{~m}$ even if there are no points present in the cell at all (such as ground or water points). Furthermore, our algorithm calculates the canopy height even if there is only a small amount of vegetation points in a cell. In rare cases, this might lead to erroneous canopy-height readings if vegetation is found on artificial structures or points have been misclassified. For example, a tall communications tower can be found just south of Aarhus, and returns from the tower were miss-classified as vegetation. The resulting canopy height for this cell is calculated as $>100 \mathrm{~m}$ above ground, which would not make sense if interpreted as a height of the vegetation above ground. For such cases, the building proportion descriptor may be used to separate cells with artificial structure from those with vegetation only. See also the "normalized_z" descriptor below for a closely related measure.

\subsubsection{Normalised height - mean and standard deviation (normalized_z_mean and normalized_z_sd)}

Similar to the canopy height descriptor, the normalised height describes the structure properties of the point cloud above ground. The key difference between the two descriptors is that for the normalised height we also included nonvegetation points (buildings and ground) and derived the summary statistic as the mean rather than the $95 \%$ quantile. For the normalised height descriptor, we also provide a measure of variation in form of the standard deviation. Specifically, we calculated the normalised mean and the standard deviation of the mean height above ground (normalised $\mathrm{z}$ attribute) for all points in each $10 \mathrm{~m} \times 10 \mathrm{~m}$ grid cell using the OPALS Cell module. The results were multiplied by 100 , rounded to the nearest integer and stored as 16 bit integers. We used the normalised $z$ attribute generated during the ingestion of the point cloud reflecting the height of a point relative to the ground level determined by the DHM/Terrain raster. Here, all points refer to all points belonging either to the ground, water, building or vegetation class. By definition the normalised height mean will be highly correlated with the "canopy_height" descriptor for cells where mainly vegetation points are present. We kept the American spelling of the descriptor name for legacy reasons with previous versions of the data set.

\subsubsection{Point counts (xxx_point_count_xxx)}

The point-count descriptors are intermediate descriptors used to generate the proportion descriptors described below. However, they can also be used to calculate tailored proportion descriptors relevant to addressing a specific ecological objective (see use-case example in Sect. 4.2). For EcoDes-DK15 
(a)

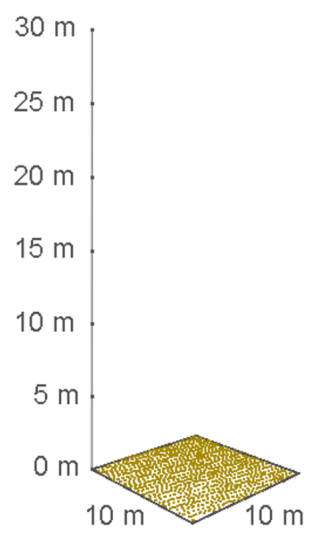

Ground Pts.

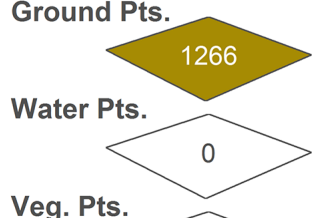

Veg. Pts.
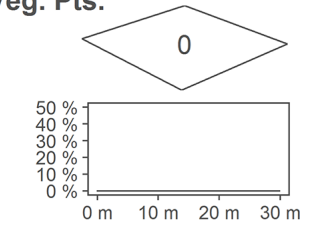

Canopy H.

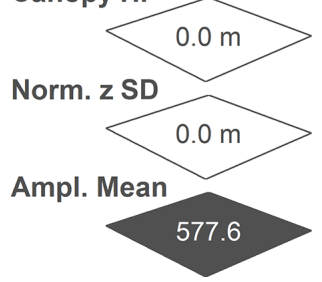

(b)
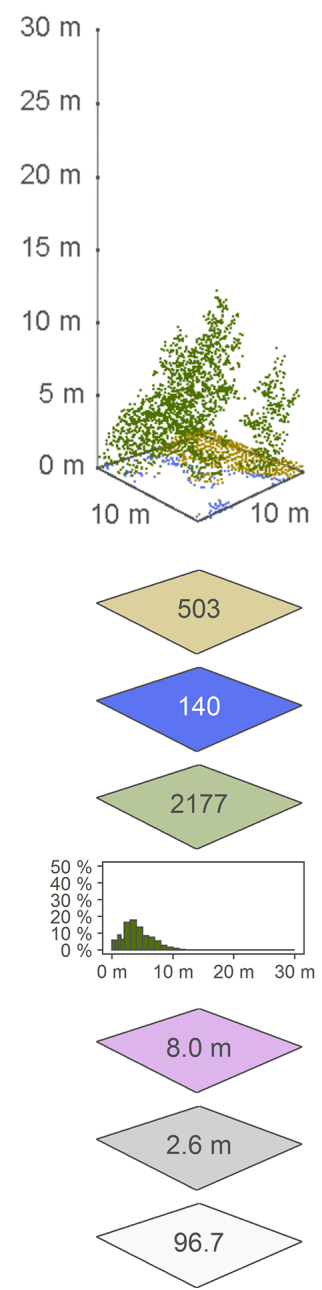

(c)
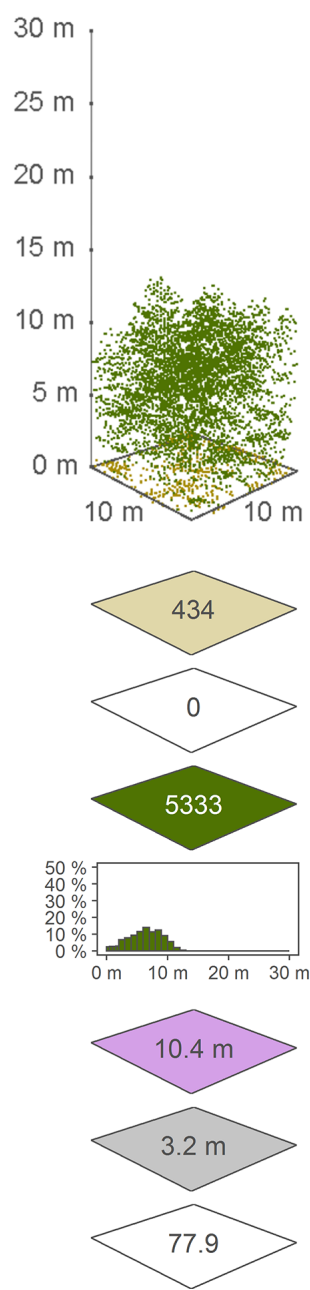

(d)
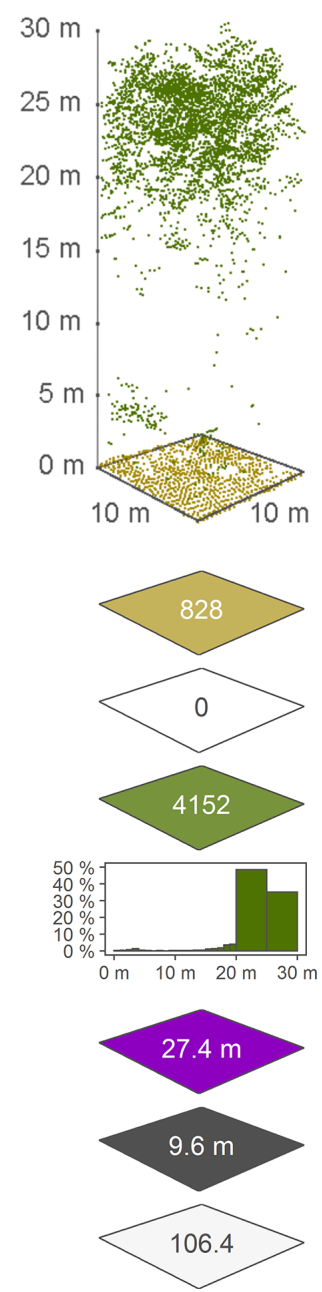

Figure 3. Point cloud examples for four $10 \mathrm{~m} \times 10 \mathrm{~m}$ cells and a selection of the associated EcoDes-DK15 descriptors derived from the point clouds, illustrating the ecological meaning and some of the limitations of the EcoDes-DK15 data set. The $10 \mathrm{~m} \times 10 \mathrm{~m}$ cells represent the following environments: (a) an agricultural field, (b) the edge of a forest/parkland pond with low vegetation, (c) a young plantation of dense coniferous trees and (d) old growth mixed woodland. The EcoDes-DK15 descriptors shown include (from the top) the total point counts for each cell in the three main EcoDes-DK15 categories: (1) the number of returns classified as ground, (2) the number of returns classified as water and (3) the number of returns classified as vegetation. In addition, the relative proportion of vegetation points per predefined height bin is illustrated below the total vegetation point count. Finally, the bottom three panels show the estimated canopy height (altitude above ground for the $95 \%$ percentile of all vegetation returns), the normalised $z$ standard deviation (variation in height above ground for all return classes) and the mean return amplitude for each cell. Please note how the classification of the point cloud does not separate between very low-growing vegetation (e.g. grass) and ground points in the agricultural field shown in (a), as well as how returns from water are only registered in shallow areas close to the water body's edge, as exemplified by the forest pond in (b). Lastly, we would like to point the reader to the general limitations of ALS in penetrating forest canopies such as those shown in (c) and (d). While the upper layers of the canopies are well resolved in both cases, the laser scanning struggles to capture some aspects of the lower layers; the ground returns were frequently blocked by the thick canopy in (c), and the laser fails to meaningfully characterise understorey vegetation and stems in (d).

we derived 30 point-count descriptors for each $10 \mathrm{~m} \times 10 \mathrm{~m}$ cell based on filtering of the pre-defined point classifications and separation by height above ground (normalised $z$ ) using the OPALS Cell module. All point counts were stored as 16 bit integers. These 30 descriptors contain 6 general point counts, including ground, water, vegetation, building and total point counts (Table 3), as well as 24 vegetation point counts separated in height bins (Table 4). Note that the number of returns within a $10 \mathrm{~m}$ cell is influenced by (a) the number of point sources present in the cell, (b) the relative position and distance of a cell to the point source when the data were collected (i.e. to the flight path), and (c) the point sources themselves (i.e. differences between the lidar sensors deployed). The absolute counts are therefore not directly 
(a) orthophoto

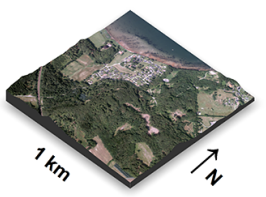

(d) canopy_height

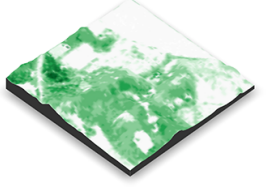

(g) ground_point_count

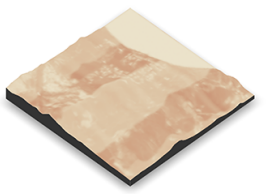

(j) building_point_count

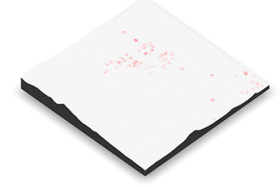

(m) canopy_openness

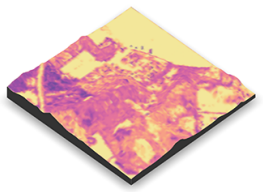

(b) amplitude_mean
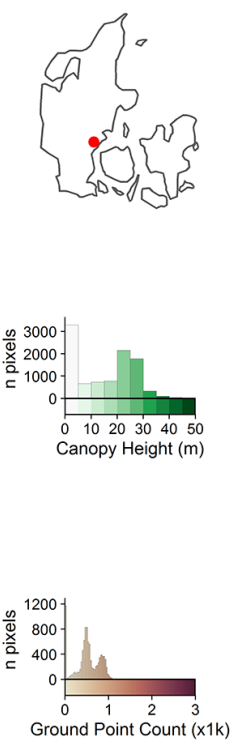

(h) water_point_count

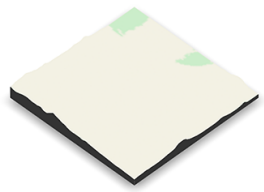

(k) total_point_count
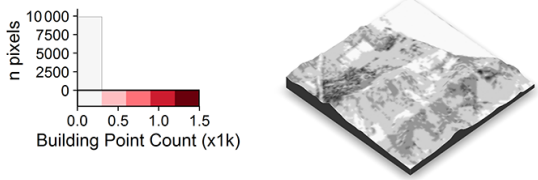

(n) vegetation_density

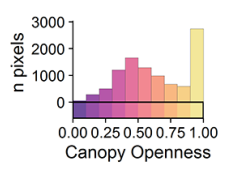

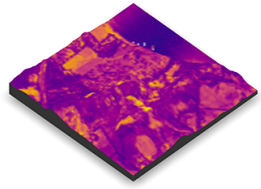

(e) normalized_z_mean
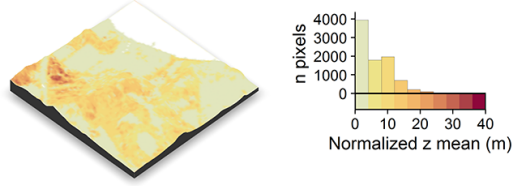

(c) amplitude_sd
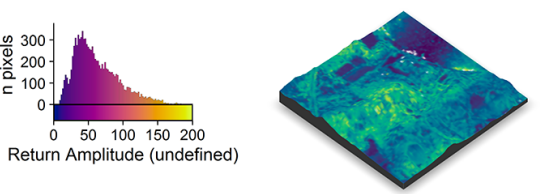

(f) normalized_z_sd
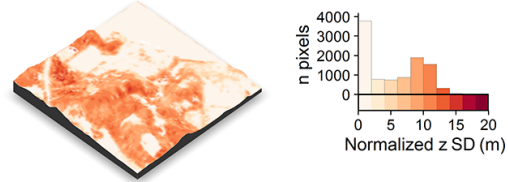

(i) vegetation_point_count
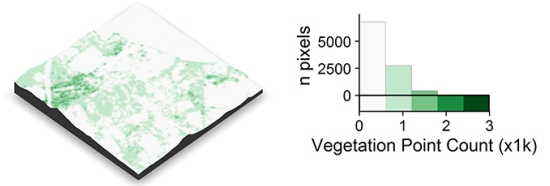

(l) point_source_nids
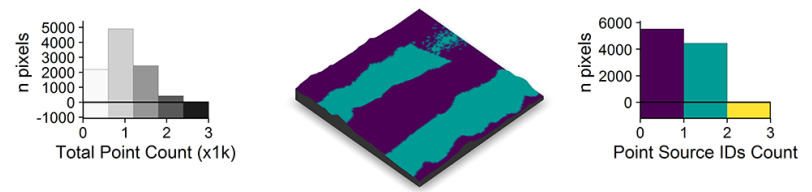

(o) building_proportion
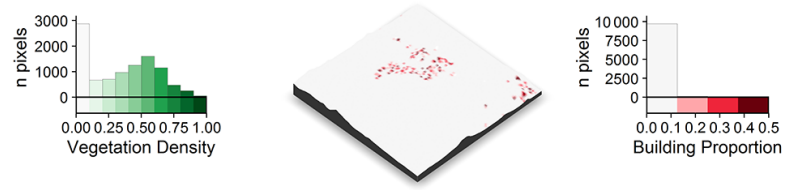

Figure 4. Illustration of the point-cloud-derived descriptors for a $1 \mathrm{~km} \times 1 \mathrm{~km}$ tile along Vejle Fjord (tile id: 6171_541). An orthophoto and the tile location relative to Denmark are shown in (a). The point-cloud-derived descriptors are comprised of (c) the mean return amplitude, (d) the standard deviation in the return amplitude, (e) the canopy height (vegetation returns only), (f) the mean of the normalized height above ground (all returns), (g) the mean of the normalized height (all returns), (h) the ground point count, (i) the water point count, (j) the building point count, (k) the total point count, (l) the number of point sources (flight strips), (m) the canopy openness, (n) the vegetation density and (o) the building proportion. Note the influence of point source overlap illustrated in (l) on some of the descriptors, for example, (g) ground point count, (i) vegetation point count and (k) total point count (see Sect. 3.5.5 for detail). For visualisation purposes, we amplified the altitude above sea level by a factor of 2 in the three-dimensional visualisations and divided the point counts by 1000 . The three-dimensional raster visualisations were generated using the rayshader v0.19.2 package in R (Morgan-Wall, 2020). Orthophotograph provided by the Danish Agency for Data Supply and Efficiency (https://sdfe.dk/hent-data/fotos-og-geodanmark-data/, last access: 28 June 2021).

comparable between cells and need to be standardised first, for example by division of the total number of point counts as done for the point proportion descriptors derived by us.

\subsubsection{Vegetation proportions by height bin (vegetation_proportion_xxx)}

The vegetation proportions by height bin are amongst the key parameters in the EcoDes-DK15 data set describing vegetation structure as they provide an indication of how the veg- etation is distributed vertically within each cell of the raster. We calculated the proportions by dividing the vegetation count for each height bin (Table 4) by the total point count (total_point_count_-01m-50m) within a given $10 \mathrm{~m} \times 10 \mathrm{~m}$ cell. Resulting proportions were multiplied by a factor of 10000 , rounded to the nearest integer and converted to 16 bit integers. All calculations were done using gdal_calc based on the respective point-count rasters (Sect. 3.3.5). The naming convention of the vegetation proportion descriptors "vegetation_proportion_xxx" follows the same convention as the 
Table 3. General point-count descriptors, as well as the height ranges and point classes included in each descriptor.

\begin{tabular}{lll}
\hline Descriptor name & Height range & Point classes \\
\hline ground_point_count_-01m-01m & -1 to $1 \mathrm{~m}$ & Ground points (class 2) \\
water_point_count_-01m-01m & -1 to $1 \mathrm{~m}$ & Water points (class 9) \\
ground_and_water_point_count_-01m-01m & -1 to $1 \mathrm{~m}$ & Ground and water points (classes 2, 9) \\
vegetation_point_count_00m-50m & 0 to $50 \mathrm{~m}$ & Vegetation points (classes 3, 4, 5) \\
building_point_count_-01m-50m & -1 to $50 \mathrm{~m}$ & Building points (class 6) \\
total_point_count_-01m-50m & -1 to $50 \mathrm{~m}$ & Ground, water, vegetation and building points (classes 2, 3, 4, 5, 6, 9) \\
\hline
\end{tabular}

Table 4. Vegetation point-count descriptors divided into 24 height bins. All vegetation point counts include the point classes 3, 4 and 5.

\begin{tabular}{ll}
\hline Descriptor name & Height range \\
\hline vegetation_point_count_00.0m-00.5m & 0.0 to $0.5 \mathrm{~m}$ \\
vegetation_point_count_00.5m-01.0m & 0.5 to $1.0 \mathrm{~m}$ \\
vegetation_point_count_01.0m-01.5m & 1.0 to $1.5 \mathrm{~m}$ \\
vegetation_point_count_01.5m-02.0m & 1.5 to $2.0 \mathrm{~m}$ \\
vegetation_point_count_02m-03m & 2 to $3 \mathrm{~m}$ \\
vegetation_point_count_03m-04m & 3 to $4 \mathrm{~m}$ \\
vegetation_point_count_04m-05m & 4 to $5 \mathrm{~m}$ \\
vegetation_point_count_05m-06m & 5 to $6 \mathrm{~m}$ \\
vegetation_point_count_06m-07m & 6 to $7 \mathrm{~m}$ \\
vegetation_point_count_07m-08m & 7 to $8 \mathrm{~m}$ \\
vegetation_point_count_08m-09m & 8 to $9 \mathrm{~m}$ \\
vegetation_point_count_09m-10m & 9 to $10 \mathrm{~m}$ \\
vegetation_point_count_10m-11m & 10 to $11 \mathrm{~m}$ \\
vegetation_point_count_11m-12m & 11 to $12 \mathrm{~m}$ \\
vegetation_point_count_12m-13m & 12 to $13 \mathrm{~m}$ \\
vegetation_point_count_13m-14m & 13 to $14 \mathrm{~m}$ \\
vegetation_point_count_14m-15m & 14 to $14 \mathrm{~m}$ \\
vegetation_point_count_15m-16m & 15 to $16 \mathrm{~m}$ \\
vegetation_point_count_16m-17m & 16 to $17 \mathrm{~m}$ \\
vegetation_point_count_17m-18m & 17 to $18 \mathrm{~m}$ \\
vegetation_point_count_18m-19m & 18 to $19 \mathrm{~m}$ \\
vegetation_point_count_19m-20m & 19 to $20 \mathrm{~m}$ \\
vegetation_point_count_20m-25m & 20 to $25 \mathrm{~m}$ \\
vegetation_point_count_25m-50m & 25 to $50 \mathrm{~m}$ \\
\hline
\end{tabular}

vegetation point-count descriptors (Table 4), whereby the suffix " $\mathrm{xxx}$ " is replaced with the respective height bin. Please note that height bins are spaced at $0.5 \mathrm{~m}$ intervals below $2 \mathrm{~m}$ and at $1 \mathrm{~m}$ intervals between 2 and $20 \mathrm{~m}$. Furthermore, the range above $20 \mathrm{~m}$ is split into only two bins: 20 to $25 \mathrm{~m}$ and 25 to $50 \mathrm{~m}$.

Given the properties of the DHM/Point-cloud we recommend being cautious when interpreting differences in the lower height bins. It is likely that the inaccuracies in the point cloud complicate clear separation between points less than half a metre apart. Furthermore, note that the proportions in the $0-0.5 \mathrm{~m}$ bin are likely biased towards an underrepresentation of the vegetation proportion in this height bin due to challenges in separating vegetation from ground points dur- ing the pre-classification. Lastly, keep in mind that dense canopy layers in the upper story of the canopy will reduce penetration of the light beam to the lower canopy layers. This may result in few returns in the lower layers (for example Fig. 3d) even though perhaps vegetation is present in those layers.

\subsubsection{Vegetation density or total vegetation proportion (vegetation_density)}

Vegetation density is an important component of ecosystem structure. Here, we calculated the vegetation density as the ratio between the vegetation returns across all vertical height bins (vegetation_point_count_00m-50m) and the total point count (total_point_count_-01m-50m). Calculations were done using gdal_calc based on the two pointcount rasters (Sect. 3.3.5). Results were multiplied by 10000 , rounded to the nearest integer and stored as 16 bit integers. In addition to the actual difference between vegetation density in a cell, the vegetation_density descriptor is also influenced by the canopy properties; e.g. a dense upper layer will prevent penetration of the light beam to lower layers or even the ground, and the point sources within a cell, e.g. multiple sources from different viewing angles, provide a more complete estimate of the vegetation density. These additional influences are important to keep in mind when interpreting the vegetation_density descriptor.

\subsubsection{Canopy openness or ground and water proportion (canopy_openness)}

Canopy openness is an important ecological descriptor particularly of forest canopies, as it describes the amount of light penetrating through to the levels of the canopy. To some degree the canopy openness serves as the inverse for the vegetation density. For EcoDes-DK15, we calculated the canopy openness of a $10 \mathrm{~m} \times 10 \mathrm{~m}$ cell as the proportion of the ground and water points (ground_and_water_point_count_$01 \mathrm{~m}-01 \mathrm{~m}$ ) to the total point count (total_point_count_-01m$50 \mathrm{~m}$ ) within the cell. The raster calculations were done using gdal_calc. Results were multiplied by 10000 , rounded to the nearest integer and stored as 16 bit integers. Please note that the same considerations as for the vegetation_density descriptor (Sect. 3.3.7) regarding canopy properties and differ- 
ences in point sources between the cells apply when interpreting the canopy_openness descriptor. In addition, it is important to note that building points will reduce the canopy openness the same way that vegetation points would.

\subsubsection{Building proportion (building_proportion)}

In a densely populated country such as Denmark, buildings form an important part of the landscape. For ecological studies the distance to buildings, their presence, absence or density may be of relevance. The building_proportion descriptor of EcoDes-DK15 provides a proxy for how much building infrastructure can be found within a $10 \mathrm{~m}$ cell. We calculated the descriptor as the number of building points (building_point_count_-01m-50m) divided by the total number of points (total_point_count_-01m-50m) within each cell using gdal_calc. Results were multiplied by 10000 , rounded to the nearest integer and stored as 16 bit integers. While most returns from three-dimensional infrastructure are classified as buildings in the DHM/Point-cloud, we would like to highlight that many roads are classified as ground (class 2) and some structures such as pylons and power lines were assigned a separate class (not described in Geodatastyrelsen, 2015). These structures are therefore not included in the building_proportion descriptor. We would further like to note that the majority of building points are likely based on returns from the roofs of the buildings. Walls and other vertical structures are probably represented at a lower frequency in the point clouds. Finally, we would like to point the reader to the "DCE Basemap" (Levin, 2019) which may assist in the identification of basic land cover types that include buildings and other man-made structures.

\subsection{Auxiliary data}

In addition to the terrain and point-cloud-derived descriptors we provide three sets of auxiliary data with EcoDes-DK15. These are four layers of ALS point source information, a mask for inland water and a sea mask, as well as a shapefile of the footprints of the $1 \mathrm{~km} \times 1 \mathrm{~km}$ tiles in the data set and their unique identifier.

\subsubsection{Point source information}

The point source attribute of the DHM/Point-cloud represents differences between sensor units or aircraft that may have been used during the nationwide lidar campaign, differences in the acquisition time and date, and differences in the viewpoint or acquisition angle of the cells. To aid in interpretation of descriptors that may be particularly influenced by point source, like the amplitude descriptors or the vegetation proportions, we provide summary information about the point sources within each $10 \mathrm{~m} \times 10 \mathrm{~m}$ cell. We summarised this information in four descriptors: "point_source_counts", "point_source_ids", "point_source_nids" and "point_source_proportions". For each tile (file name suffix = tile id), these descriptors are found in four subfolders bundled up in the parent "point_source_info" folder.

The point_source_ids is the multi-layer raster containing one 16 bit integer layer for each point source id found in a tile. If a point with a given point source id is present, the value of the cell is set to the point source id (an integer number) in the respective layer for the point source id; otherwise the value of a cell is set to 0 . This multilayer raster can be used to match the file names of the point_source_counts and point_source_proportions rasters to a given point source id. Point source ids were extracted using Opals Cell.

The point_source_nids is the single layer GeoTIFF files containing the number of different point source ids in each cell stored as 16 bit integers. We calculated the number of point source ids based on the point_source_ids descriptor using gdal_calc.

For point_source_counts, for each tile there are multiple rasters (up to four), one raster for each point source id found in the point cloud of the tile (see the point_source_ids descriptor). These rasters are named with an additional suffix, which matches the integer point source id for which the point counts are given in the raster

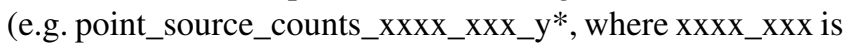
the tile id and $y^{*}$ the integer point source id). The rasters contain the number of points per $10 \mathrm{~m} \times 10 \mathrm{~m}$ cell for the respective point source id in the tile. Counts were extracted using the OPALS Cell module and stored as 16 bit integers.

For point_source_proportions, for each tile there are multiple rasters (up to four), one raster for each point source id found in the point cloud of the tile (see the point_source_ids descriptor). These rasters are named with an additional suffix, which matches the integer point source id for which the point proportions are given in the raster (e.g. point_source_proportions_xxxx_xxx_y*, where $\mathrm{xxxx}_{\mathrm{x}} \mathrm{xxx}$ is the tile id and $\mathrm{y}^{*}$ the integer point source id). Each raster contains the proportion of the point counts for a given point source id in relation to the total point count per $10 \mathrm{~m} \times 10 \mathrm{~m}$ cell. Calculations were carried out using gdal_calc. The final proportions were multiplied by a factor of 10000 , rounded to the nearest integer and stored as 16 bit integers.

\subsubsection{Water masks (inland_water_mask and sea_mask)}

We also provide rasterised water masks for use cases that require masking inland water bodies or the sea. To represent all permanent lakes in Denmark, we merged three shapefiles containing (1) lakes protected by the Danish nature protection legislation ( $\$ 3$, available at https://arealinformation. miljoeportal.dk, last access: 28 June 2021), (2) other valuable lakes (available on request at the Danish Farming Agency in the "good farming and environmental condition" data set), and (3) a layer containing the remaining rather small lakes 
and ponds (GeoDanmark, https://kortforsyningen.dk/, last access: 28 June 2021). The combined shapefile is provided on the GitHub code repository (see below). We then burned the geometries within the shapefile into the $10 \mathrm{~m} \times 10 \mathrm{~m}$ grid using gdal_rasterize. The masks are binary: a cell value of 1 indicates land and a value of -9999 (NoData) indicates sea or inland water, respectively. When using the masks please consider that the shape, presence and absence of water bodies and coastlines may fluctuate over time. We created the masks to present a snapshot of the water bodies as close as possible to the time point of the DHM/Point-cloud acquisition (spring 2014-summer 2015), but inaccuracies may still arise. When combining the data with more recent observations, keep in mind that inland water bodies and coastlines may have changed since then. Finally, while we aimed to produce the inland water mask to be as comprehensive as possible, some small ponds and water bodies may have been missed. Note also that while some rivers are included in the sea mask, the inland water mask does not include rivers or streams. The masks can be found in the "masks" subfolder of the complete data set.

\subsubsection{Vegetation point date stamps (date_stamp_min, date_stamp_max, date_stamp_mode)}

The time point at which the source data were collected may be of interest to certain applications that are using EcoDesDK15 vegetation descriptors. These include, for example, comparisons amongst regions where the data were collected under different foliage conditions (leaf-on/leaf-off) or studies that require a precise timing of the sample such as change detection studies. To better facilitate these applications, we generated three date_stamp descriptors that summarise the GPS time stamps of the vegetation points within each $10 \mathrm{~m} \times 10 \mathrm{~m}$ cell. The three descriptors are date_stamp_min, date_stamp_max and date_stamp_mode, which represent the earliest, latest and most common survey date for the vegetation points in any given cell in the format "YYYYMMDD", where YYYY is the year in four digits, MM the month in two digits and DD the day in two digits.

We used the OPALS addInfo module to generate a new "GPSDay" attribute for all vegetation points (classes 3, 4, 5) by dividing the GPS time (seconds since 6 January 1980) attribute by 86400 (seconds per day) and taking the floor value of the result. We then exported the min, max and mode for each $10 \mathrm{~m} \times 10 \mathrm{~m}$ cell using the OPALS Cell module, loaded the output rasters into Python and converted the_GPSDay values into year, month and day in central European time (CET) using the datetime module. Finally, we exported the min, max and mode dates as 32 bit integers.

Note that the date_stamp descriptors only cover points that are classified as vegetation and therefore do not provide information about the time point at which points belonging to other classes were surveyed (ground point, building points, etc). We chose to not include other point classes in

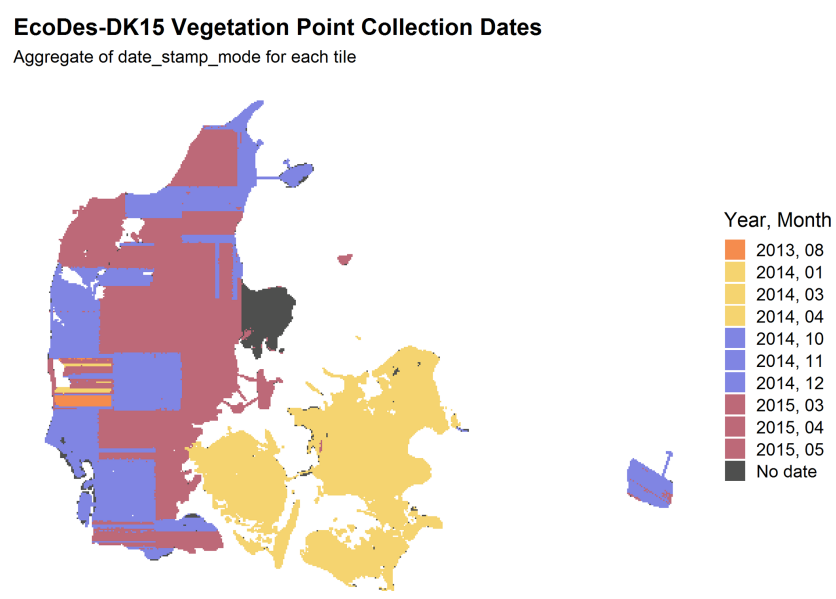

Figure 5. Distribution of the most common survey date for the vegetation points in each tile of the EcoDes-DK15 data set. The data shown are aggregated for each tile from date_stamp_mode descriptor. The figure highlights that while the majority of the vegetation points are from 2014/15, the data set also includes a small amount of vegetation points from 2013 in western Jutland. Furthermore, surveys were conducted in all seasons, with vegetation points originating in spring, summer, autumn and winter. Nonetheless, the majority of vegetation points come from the leaf-off season. Lastly, the date_stamp descriptors could not be derived for some regions as the GPS time was not provided in the point clouds. However, from auxiliary information we know that the surveys in the Mols Bjerge and Sønderborg areas were conducted in April-May 2015 and October 2014 , respectively.

the date_stamp descriptors as we are aware that all versions of the source data sets include some ground points from 2007 and as we believe that clear information about the vegetation points is most relevant for the end-users conducting ecological research. Furthermore, determining the date_stamps was not possible for a proportion of tiles for which the GPS time in the source data was not converted from seconds per GPS week to GPS time in seconds since 6 January 1980. A post hoc conversion is not possible without the knowledge of the exact GPS week number, which is not provided in the source data. In these cases, we assigned the NoData value to the date_stamps. The majority of the tiles affected are located in the areas around Mols Bjerge and Sønderborg (Fig. 5). However, from auxiliary information about the source data sets we know that these areas were surveyed April-May 2015 and October 2014, respectively.

\subsubsection{Footprint file (tile_footprints.shp)}

To assist data access and creation of data subsets, we have produced an ESRI shapefile containing the footprints of all $1 \mathrm{~km} \times 1 \mathrm{~km}$ tiles in the EcoDes-DK15 data set. The shapefile was generated based on the "dtm_10m" rasters, and the tile identifier of each footprint geometry is specified in the "tile_id" attribute column. 


\section{Data access and ecological use case example}

\subsection{Data access and handling}

Depending on the extent of the study, it may be preferable to work with a subset of the data set rather than the nationwide VRT files (Fig. 6). We suggest starting by identifying the relevant EcoDes-DK15 descriptors of interest, then retrieving the relevant data from the repository and decompressing the archives (instructions provided on data repository). If the study area of interest covers a large fraction of Denmark's extent and sufficient processing power is available, the nationwide VRT data should provide the most convenient access to the selected descriptors. However, if the study area does not cover a large proportion of Denmark, then we suggest subsetting the data using the tile footprints to decrease demands on computational resources. After subsetting, local/regional VRT files or mosaics can be generated if needed. We provide an example R script illustrating how this subsetting could be done for the use case example shown in the next section on the code repository (manuscript/figure_7/subset_data set.R). We have also made the resulting subset available as a "teaser" (5 MB) to help the reader assess the value of EcoDes-DK15 without having to commit to the multi-gigabyte download of the complete data set (see Sect. 6).

\subsection{Use case example - ecological landscape stratification of Husby Klit nature protected area}

Figure 7 illustrates a use case for the EcoDes-DK15 data set with an example of an ecologically motivated landscape stratification of the "Husby Klit" old-dune protected area in western Denmark. We developed this stratification for a group of master's projects carrying out vegetation monitoring in the area. Our aim was to capture the variation in the dominant vegetation based on vegetation structure, as well as the variation in fine-scale topography created by the dune systems across the landscape. In addition to using the descriptors already provided, the stratification required us to derive a topographic position index, as well as grouping the point densities in height bins relevant to the characteristics of the three most common dominant vegetation types (grass and heath, Pinus mugo Turra, Pinus sylvestris L.) in the area. The source code for this figure contained in the code repository provides an example of how this can be achieved (manuscript/figure_7/figure_7.R).

\section{Discussion - limitations and future perspectives}

Our data set demonstrates how the complex information in ALS point cloud data sets spanning more than $40000 \mathrm{~km}^{2}$ can be condensed into a compact data set of rasterised descriptors of interest for ecological studies. For the whole of Denmark, we provide 70 raster layers representing 18 measures that describe a snapshot of vegetation height, structure

\section{Data access}

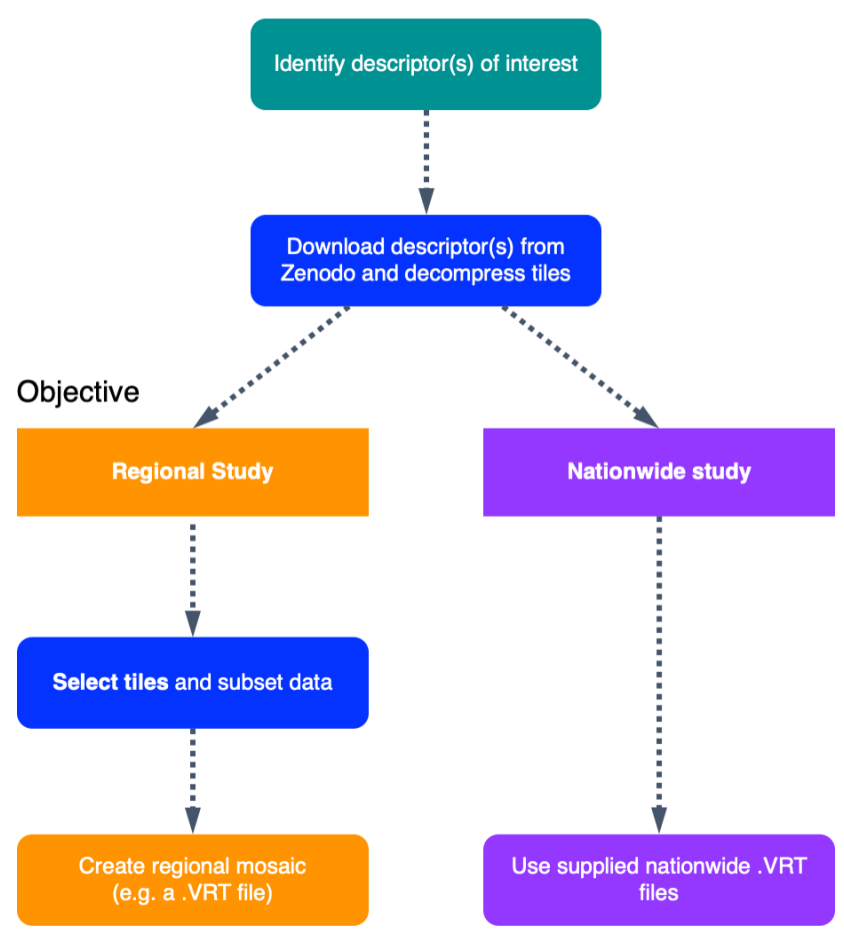

Figure 6. Schematic chart of two possible approaches for accessing and integrating EcoDes-DK15 data into ecological studies. The first step is to identify which descriptors are of interest; these descriptors can then be downloaded from the Zenodo repository and decompressed. Next a decision needs to be made whether the whole data set (nationwide) or only a subset of the tiles is required (e.g. a regional study). As the whole data set is relatively large ( $\sim 94 \mathrm{~GB})$, storage and processing limitations need to be taken into account when planning data processing and handling. If a subset of tiles is sufficient for a study, the provided tile footprints can be used to identify which tiles are required based on a geometry (e.g. a shapefile) of the study region(s). Finally, for easy data handling in subsequent analysis, a mosaic of the selected tiles can be created. For nationwide use we provided virtual mosaics (VRT files) containing all tiles for the descriptors. An R script illustrating how the subsetting can be done for a regional study can be found on the GitHub repository: https://github.com/jakobjassmann/ ecodes-dk-lidar/blob/master/manuscript/figure_7/subset_dataset.R (last access: 5 January 2022).

and density, as well as topography and topography-derived habitat characteristics, including slope, aspect, solar radiation and wetness for the time period 2014-2015. These measures are of direct relevance for ecological research on species' habitat characteristics, distribution modelling, biodiversity and conservation applications. Condensing the ALSderived information into a compact set of raster descriptors makes it more accessible to the community of ecological researchers and practitioners, allowing them to access information on the vertical structure of vegetation and terrain other- 
(a) Topography

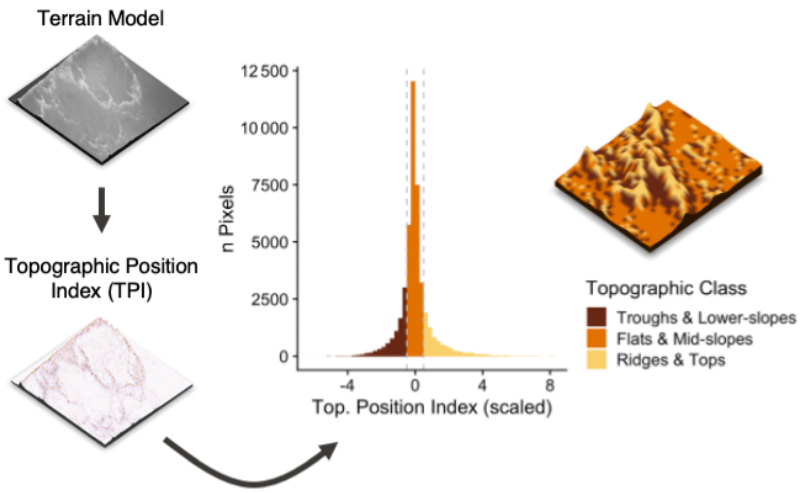

(b) Vegetation Structure

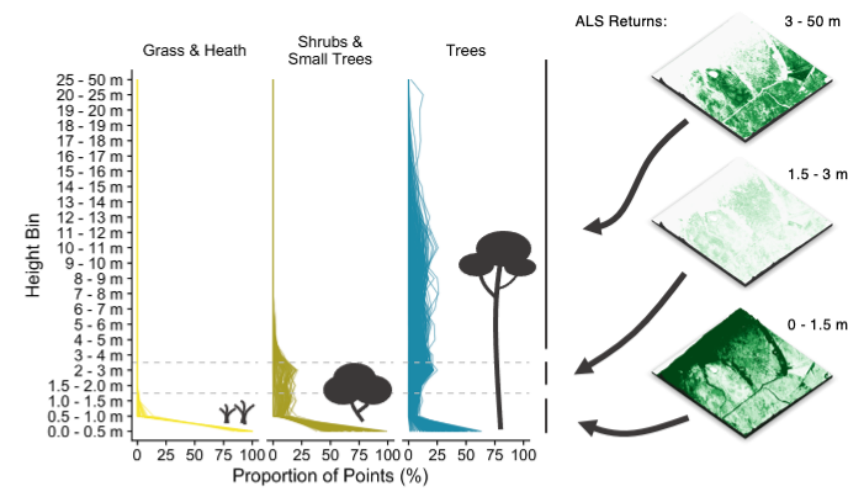

(c) Landscape Classification

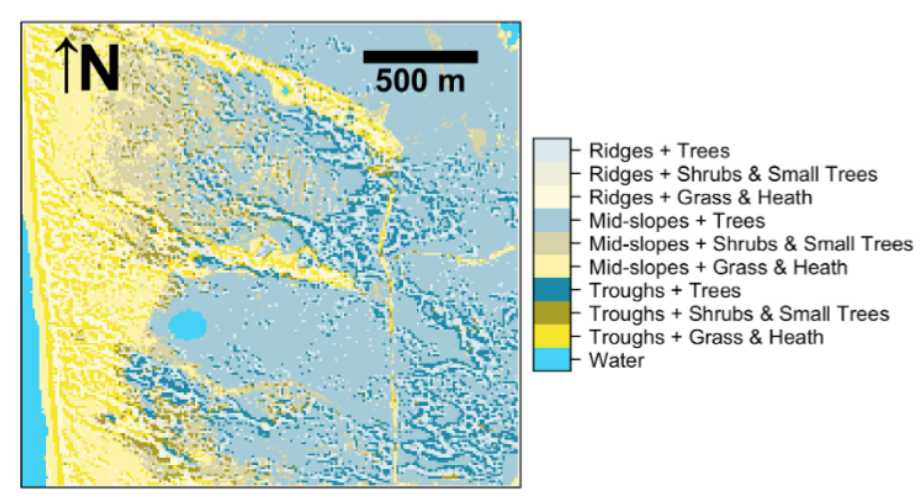

(d) Location within Denmark

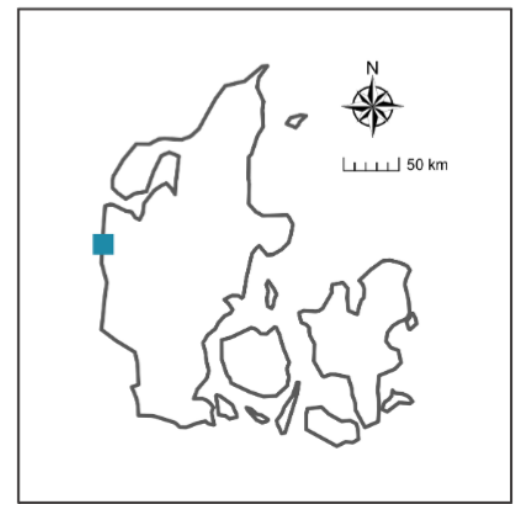

Figure 7. Use-case example: landscape stratification of the Husby Klit protected area based on EcoDes-DK15-derived terrain and vegetation structure descriptors. The target was to stratify the landscape of the Husby Klit "dune plantation" area in the west of Denmark (56.2837$56.3024^{\circ} \mathrm{N}, 8.1239-8.1600^{\circ} \mathrm{E}$ ) to facilitate stratified random sampling for vegetation monitoring. We identified the four tiles overlapping with the boundaries of the protected area and derived a stratification based on two components: topographic position (a) and vegetation structure (b). We hypothesised that both components would influence the vegetation communities present. For the topographic position (a), we first derived and standardised the topographic position index (TPI) (Weiss, 2001) from the terrain model (dtm_10m). Following Weiss (2001) we then classified each cell based on the scaled TPI into three categories. A scaled TPI below a value of -0.5 was classified as a "trough or lower-slope", a scaled TPI between -0.5 and 0.5 as "mid-slope or flat", and a scaled TPI above 0.5 as a "ridge or top". For the vegetation structure component (b), we calculated the proportion of returns in three simplified height bins: (1) 0 to $1.5 \mathrm{~m}$, (2) 1.5 to $3.0 \mathrm{~m}$ and (3) 3.0 to $50 \mathrm{~m}$. Here we included both ground and vegetation returns as the divisor for the standardisation but not the returns from buildings or water. Based on a priori knowledge we deduced that there are three dominant vegetation communities within the protected area: communities dominated by grass and heath with vegetation growth generally below $1.5 \mathrm{~m}$, communities dominated by shrubs and small trees (including the invasive Pinus mugo) with vegetation growth predominantly below $3.0 \mathrm{~m}$, and communities dominated by trees (including the native Pinus sylvestris), generally with growth above $3.0 \mathrm{~m}$. We used this knowledge to assign the three vegetation classes based on the proportion of point returns in the simplified height bins. For the "grass and heath" class we used a strict cut-off with no points present above $1.5 \mathrm{~m}$. For the "shrubs and small trees" class we used a fuzzy cut-off allowing the proportion of points in the $3.0 \mathrm{~m}$ and above bin to reach up to $10 \%$ of the maximum proportion found in this height bin. All remaining cells were then assigned to the "trees" class. Finally, we combined the two classifications into one as illustrated in (c). Panel (d) shows the location of the protected area within Denmark. The three-dimensional raster visualisations were generated using the rayshader v0.19.2 package in R (Morgan-Wall, 2020).

wise difficult to obtain for large extents such as those of a whole country.

We would like to highlight some key ecological and physical limitations that should be kept in mind when using the data or derivatives. Firstly, we were able to only carry out a simple qualitative assessment of the errors in the EcoDesDK15 data set within the scope of this project. All descrip- tors should therefore be seen as proxies for the geographical and biological properties they describe. Errors in the original point cloud and DTM will have propagated through to the final descriptors, and future studies are needed to assess to what degree the proxy measures correlate with in-field data. Furthermore, the EcoDes-DK15 data set is a snapshot in time representing the state of the vegetation in the 1.5 years be- 
tween spring 2014 and summer 2015 (with some exceptions in western Jutland, where the data are from 2013). Like anywhere on Earth, the landscapes of Denmark may change over time, and by the time of publication of this data set over 5 years may have passed since the collection of the source data. External data sources containing information about ongoing or past changes (such as satellite imagery - see below) might help overcome this bias. Additionally, the geographical differences in the timing of the point cloud collection across the country (see Sect. 6.3.4) may introduce noise and could affect cross-comparability of the data between regions, for example due to seasonal differences in foliage (see, for example, Leiterer et al., 2015). Furthermore, there are implicit limitations in spatial scale due to the set grain size of the data set. We chose a $10 \mathrm{~m} \times 10 \mathrm{~m}$ grid for efficiency in computation and data handling, as well as to overcome limitations in the density of the source point cloud (four to five points per square metre). Our data set might therefore not serve well for capturing some ecologically relevant variation in terrain and vegetation structures at scales below the $10 \mathrm{~m} \times 10 \mathrm{~m}$ grain size. We believe that our data set is nonetheless valuable in providing ecologically relevant information at the geographical extent of Denmark.

While some of the descriptors in the presented data set such as elevation, slope and vegetation height are quite straightforward to interpret, the ecological meaning of other descriptors - for example those related to vegetation structure - may not be as obvious as they are influenced by multiple ecological and sensing methodology-related factors. The amplitude, point count and point proportion descriptors are amongst those measures. For example, while the (noncalibrated) amplitude in the DHM/Point-cloud source data may generally relate to the reflectance properties of the surface that generated the return, the incident light angle, scattering and subsequent generation of echoes may result in several different surfaces generating similar amplitude signatures. Furthermore, the point counts may be influenced by a whole suite of factors, including incident light angle, scattering and density of flight strips covering a given cell, as well as canopy properties - most importantly the penetration ability. While standardising the point counts as proportions to the total counts may help to account for some of these factors, it is likely that notable uncertainties will remain even in the proportions especially for lower layers of the canopy. Nonetheless, we believe that these measures can be informative if appropriate care is taken in their interpretation.

Two code developments could enhance the EcoDes-DK15 processing workflow in efficiency and transferability: using gdal Python bindings and switching to an open-source point cloud handler. First, for practical reasons we reverted to using gdal binaries rather than the Python bindings as we encountered issues with the gdal bindings provided by the OPALS shell on our computational server. Solving this issue and using the bindings instead of the binaries could reduce hard drive access time and overheads from launching sub- processes and therefore potentially speed up the raster manipulations in the workflow. However, as the point cloud processing takes the majority of time (we estimate $75 \%-80 \%$ ) we did not invest further resources to do so in the first development round. Secondly, while our Python source code is open source and freely available, OPALS itself requires the purchase of a software license, limiting the transferability of our code to projects which can afford the license. We did not explore alternatives to OPALS, but a redeveloped processing pipeline could make use of purely open-source software benefiting from ongoing developments in the field; see, for example, the "Laserchicken" Python module (Meijer et al., 2020) and "lidR" R package (Roussel et al., 2020).

We believe that to realise the full potential of ALS-derived data such as EcoDes-DK15 these data sets are ideally combined with other data sources including climate, field data and remote sensing observations. Climate data are especially relevant for addressing research on species-habitat relationships, distribution models and biodiversity studies, and many studies have demonstrated the power of ALS observations in complementing climate data for such exercises (Coops et al., 2016; Zellweger et al., 2016). Like for other remote sensing products, field data are essential for validating inferences and putting biological meaning into ALS data (Coops et al., 2021) - this applies especially to the more complex structural vegetation measures in EcoDes-DK15. This could be achieved through field surveys combined with terrestrial- and drone-based ALS data, in which the point density is much higher (e.g. Madsen et al., 2020). The potential benefits from fusing ALS data with other remote sensing products have been realised early on (Hyde et al., 2005) and demonstrated again since then (e.g. Coops et al., 2021; Montgomery et al., 2019; Manzanera et al., 2016). However, note that data fusion does not provide additional value in every use case (Xu et al., 2018; Ceballos et al., 2015; Boelman et al., 2016). We still believe that there is tremendous potential in combining EcoDes-DK15 with other types of remote sensing data. Finegrain optical imagery could provide proxies for horizontal vegetation structure in grasslands where the vegetation is too small to be captured by the DHM/Point-cloud density (e.g. Malmstrom et al., 2017; Pazúr et al., 2021), and satellitederived time series can provide unique temporal perspectives that describe parameters of seasonality (e.g. Boelman et al., 2016) and the historical context on disturbances and landcover change not captured in the single time-point ALS data (e.g. Senf et al., 2017; Pekel et al., 2016).

\section{Code availability}

The source code for the processing pipeline is openly available under a simplified BSD license via Zenodo: https://doi.org/10.5281/zenodo.6035002 (Assmann et al., 2022b). 


\section{Data availability}

The data are openly available under a Creative Commons Attribution 4.0 license on Zenodo: https://doi.org/10.5281/zenodo.4756556 (Assmann et al., 2021).

A small example subset "teaser" (5 MB) covering the $9 \mathrm{~km} \times 9 \mathrm{~km}$ of the Husby Klit area (Fig. 7) is available on Zenodo: https://doi.org/10.5281/zenodo.6035188 (Assmann et al., 2022a).

\section{Conclusions}

Open data sets like EcoDes-DK15 will allow ecologists with limited computational resources and little expertise in handling lidar point clouds to use large-scale ALS data for their research. We see our efforts not only as a first step for providing ready-to-use descriptors of local vegetation and terrain features but also for providing an example workflow and tools that allow for the replication of the processing. We have described and documented the measures of terrain and vegetation structure contained in the data set and pointed out possible applications and limitations. We are confident that EcoDes-DK15 provides a meaningful collection of ecological descriptors at a $10 \mathrm{~m} \times 10 \mathrm{~m}$ resolution for the extent of a whole country, and we encourage the community to use our workflow and collection of codes as inspiration to process other large-scale ALS data sets in a similar manner. U1timately, we hope the publication of this data set will help facilitate the uptake of ALS-derived information by ecological researchers and practitioners in Denmark and beyond.

Author contributions. JJA, JEM, UAT and SN developed the data set with focus on its ecological relevance, providing input on the ecological meaning, spatial scale and calculation of the descriptors. JJA developed the code with input from JEM. JJA carried out the computations. JJA led the writing and revisions of the manuscript, with JEM, UAT and SN contributing to the manuscript writing and revisions in a collaborative manner. SN provided funding and supervision for this project.

Competing interests. The contact author has declared that neither they nor their co-authors have any competing interests.

Disclaimer. Publisher's note: Copernicus Publications remains neutral with regard to jurisdictional claims in published maps and institutional affiliations.

Acknowledgements. We would like to thank Andràs Zlinszky for his contributions to earlier versions of the data set, Charles Davison for feedback regarding data use and handling, and Matthew Barbee and Zsófia Koma for sharing their insights on the source data merger and Zsófia's script to generate summary statistics for the different versions of the DHM point clouds.

Financial support. This research has been supported by the Aarhus Universitets Forskningsfond (grant no. AUFF-E-2015-FLS8-73), the Novo Nordisk Fonden (grant no. NNF20OC0059595) and the Carlsbergfondet (Distinguished Associate Professor Fellowship to Signe Normand).

Review statement. This paper was edited by David Carlson and reviewed by Yifang Shi and Vitezslav Moudry.

\section{References}

Ackermann, F.: Airborne laser scanning - present status and future expectations, ISPRS J Photogramm., 54, 64-67, https://doi.org/10.1016/S0924-2716(99)00009-X, 1999.

ASPRS: LAS Specification Version 1.3 - R11, American Society for Photogrammetry \& Remote Sensing, Bethesda, Maryland, 2011.

ASPRS: LAS Specification 1.4 - R14, American Society for Photogrammetry and Remote Sensing, Bethesda, Maryland, 2019.

Assmann, J. J., Moeslund, J. E., Treier, U. A., and Normand, S.: EcoDes-DK15: High-resolution ecological descriptors of vegetation and terrain derived from Denmark's national airborne laser scanning data set (1.1.0), Zenodo [data set], https://doi.org/10.5281/zenodo.5752926, 2021.

Assmann, J. J., Moeslund, J. E., Treier, U. A., and Normand, S.: EcoDes-DK15 v1.1.0 Teaser Dataset (Husby Klit), Zenodo [data set], https://doi.org/10.5281/zenodo.6035188, 2022a.

Assmann, J. J., Moeslund, J. E., Treier, U. A., and Normand, S.: jakobjassmann/ecodes-dk-lidar: EcoDes-DK15 v1.1.0, Zenodo [code], https://doi.org/10.5281/zenodo.6035002, 10 February $2022 b$.

Bakx, T. R. M., Koma, Z., Seijmonsbergen, A. C., and Kissling, W. D.: Use and categorization of Light Detection and Ranging vegetation metrics in avian diversity and species distribution research, Divers. Distrib., 25, 1045-1059, https://doi.org/10.1111/ddi.12915, 2019.

Beven, K. J. and Kirkby, M. J.: A physically based, variable contributing area model of basin hydrology / Un modèle à base physique de zone d'appel variable de l'hydrologie du bassin versant, Hyrdol. Sci. B., 24, 43-69, https://doi.org/10.1080/02626667909491834, 1979.

Boelman, N. T., Holbrook, J. D., Greaves, H. E., Krause, J. S., Chmura, H. E., Magney, T. S., Perez, J. H., Eitel, J. U. H., Gough, L., Vierling, K. T., Wingfield, J. C., and Vierling, L. A.: Airborne laser scanning and spectral remote sensing give a bird's eye perspective on arctic tundra breeding habitat at multiple spatial scales, Remote Sens. Environ., 184, 337-349, https://doi.org/10.1016/j.rse.2016.07.012, 2016.

Böhner, J. and Selige, T.: Spatial Prediction Of Soil Attributes Using Terrain Analysis And Climate Regionalisation, Göttinger Geographische Abhandlungen, 115, 13-120, 2006.

Ceballos, A., Hernández, J., Corvalán, P., and Galleguillos, M.: Comparison of Airborne LiDAR and Satellite Hyperspectral Re- 
mote Sensing to Estimate Vascular Plant Richness in Deciduous Mediterranean Forests of Central Chile, Remote Sens.-Basel, 7, 2692-2714, https://doi.org/10.3390/rs70302692, 2015.

Conrad, O., Bechtel, B., Bock, M., Dietrich, H., Fischer, E., Gerlitz, L., Wehberg, J., Wichmann, V., and Böhner, J.: System for Automated Geoscientific Analyses (SAGA) v. 2.1.4, Geosci. Model Dev., 8, 1991-2007, https://doi.org/10.5194/gmd-8-1991-2015, 2015.

Coops, N. C., Tompaski, P., Nijland, W., Rickbeil, G. J. M., Nielsen, S. E., Bater, C. W., and Stadt, J. J.: A forest structure habitat index based on airborne laser scanning data, Ecol. Indic., 67, 346357, https://doi.org/10.1016/j.ecolind.2016.02.057, 2016.

Coops, N. C., Tompalski, P., Goodbody, T. R. H., Queinnec, M., Luther, J. E., Bolton, D. K., White, J. C., Wulder, M. A., van Lier, O. R., and Hermosilla, T.: Modelling lidar-derived estimates of forest attributes over space and time: A review of approaches and future trends, Remote Sens. Environ., 260, 112477, https://doi.org/10.1016/j.rse.2021.112477, 2021.

Flatman, A., Rosenkranz, B., Evers, K., Bartels, P., Kokkendorff, S., Knudsen, T., and Nielsen, T.: Quality assessment report to the Danish Elevation Model (DK-DEM), Agency for Data Supply and Efficiency, Copenhagen, Denmark, 2016.

Freeman, T. G.: Calculating catchment area with divergent flow based on a regular grid, Comput. Geosci., 17, 413-422, https://doi.org/10.1016/0098-3004(91)90048-I, 1991.

Froidevaux, J. S. P., Zellweger, F., Bollmann, K., Jones, G., and Obrist, M. K.: From field surveys to LiDAR: Shining a light on how bats respond to forest structure, Remote Sens. Environ., 175, 242-250, https://doi.org/10.1016/j.rse.2015.12.038, 2016.

GDAL/OGR contributors: GDAL/OGR Geospatial Data Abstraction software Library, Open Source Geospatial Foundation, Zenodo [code], https://doi.org/10.5281/zenodo.5884351, 2022.

Geodatastyrelsen: Dataspecifikation for Danmarks Højdemodel Punktsky, Data version 2.0 - Januar 2015, Geodatastyrelsen, Copenhagen, https://kortforsyningen.dk/sites/default/files/old_ gst/DOKUMENTATION/Data/dk_dhm_punktsky_v2_jan_ 2015.pdf (28 June 2021), 2015.

Grohmann, C. H.: Effects of spatial resolution on slope and aspect derivation for regional-scale analysis, Comput. Geosci., 77, 111117, https://doi.org/10.1016/j.cageo.2015.02.003, 2015.

Gruber, S. and Peckahm, S.: Land-Surface Parameters and Objects in Hydrology, in: Geomorphometry: Concepts, Software, Applications, edited by: Hengl, T. and Reuter, H. I., Elsevier, 33, 293308,2008 .

Guo, X., Coops, N. C., Tompalski, P., Nielsen, S. E., Bater, C. W., and John Stadt, J.: Regional mapping of vegetation structure for biodiversity monitoring using airborne lidar data, Ecol. Inform., 38, 50-61, https://doi.org/10.1016/j.ecoinf.2017.01.005, 2017.

Haralick, R. M.: Ridges and valleys on digital images, Comput. Vision Graph., 22, 28-38, https://doi.org/10.1016/0734189X(83)90094-4, 1983.

Horn, B. K. P.: Hill shading and the reflectance map, P. IEEE, 69, 14-47, https://doi.org/10.1109/PROC.1981.11918, 1981.

Hyde, P., Dubayah, R., Peterson, B., Blair, J. B., Hofton, M., Hunsaker, C., Knox, R., and Walker, W.: Mapping forest structure for wildlife habitat analysis using waveform lidar: Validation of montane ecosystems, Remote Sens. Environ., 96, 427-437, https://doi.org/10.1016/j.rse.2005.03.005, 2005.
IPBES: Global assessment report on biodiversity and ecosystem services of the Intergovernmental Science-Policy Platform on Biodiversity and Ecosystem Services., edited by: Brondizio, E. S., Díaz, S., and Settele, J., IPBES secretariat, Bonn, Germany, https://doi.org/10.5281/zenodo.3831673, 2019.

Kopecký, M., Macek, M., and Wild, J.: Topographic Wetness Index calculation guidelines based on measured soil moisture and plant species composition, Sci. Total Environ., 143785, https://doi.org/10.1016/j.scitotenv.2020.143785, 2020.

Leiterer, R., Furrer, R., Schaepman, M. E., and Morsdorf, F.: Forest canopy-structure characterization: A datadriven approach, Forest Ecol. Manage., 358, 48-61, https://doi.org/10.1016/j.foreco.2015.09.003, 2015.

Leutner, B. F., Reineking, B., Müller, J., Bachmann, M., Beierkuhnlein, C., Dech, S., and Wegmann, M.: Modelling Forest $\alpha$ Diversity and Floristic Composition - On the Added Value of LiDAR plus Hyperspectral Remote Sensing, Remote Sens.-Basel, 4, 2818-2845, https://doi.org/10.3390/rs4092818, 2012.

Levin, G.: Basemap03. Technical documentation of the method for elaboration of a land-use and land-cover map for Denmark. Aarhus University, DCE - Danish Centre for Environment and Energy, Aarhus, Denmark, 86 pp., Technical Report No. 159, http://dce2.au.dk/pub/TR159.pdf (last access: 10 February 2022), 2019.

Lin, Y., Vosselman, G., Cao, Y., and Yang, M. Y.: Active and incremental learning for semantic ALS point cloud segmentation, ISPRS J Photogramm., 169, 73-92, https://doi.org/10.1016/j.isprsjprs.2020.09.003, 2020.

Lopatin, J., Dolos, K., Hernández, H. J., Galleguillos, M., and Fassnacht, F. E.: Comparing Generalized Linear Models and random forest to model vascular plant species richness using LiDAR data in a natural forest in central Chile, Remote Sens. Environ., 173, 200-210, https://doi.org/10.1016/j.rse.2015.11.029, 2016.

Madsen, B., Treier, U. A., Zlinszky, A., Lucieer, A., and Normand, S.: Detecting shrub encroachment in seminatural grasslands using UAS LiDAR, Ecol. Evol., 10, 4876-4902, https://doi.org/10.1002/ece3.6240, 2020.

Malmstrom, C. M., Butterfield, H. S., Planck, L., Long, C. W., and Eviner, V. T.: Novel fine-scale aerial mapping approach quantifies grassland weed cover dynamics and response to management, PLOS ONE, 12, e0181665, https://doi.org/10.1371/journal.pone.0181665, 2017.

Manzanera, J. A., García-Abril, A., Pascual, C., Tejera, R., MartínFernández, S., Tokola, T., and Valbuena, R.: Fusion of airborne LiDAR and multispectral sensors reveals synergic capabilities in forest structure characterization, GISci. Remote Sens., 53, 723738, https://doi.org/10.1080/15481603.2016.1231605, 2016.

Mao, L., Dennett, J., Bater, C. W., Tompalski, P., Coops, N. C., Farr, D., Kohler, M., White, B., Stadt, J. J., and Nielsen, S. E.: Using airborne laser scanning to predict plant species richness and assess conservation threats in the oil sands region of Alberta's boreal forest, Forest Ecol. Manag., 409, 29-37, https://doi.org/10.1016/j.foreco.2017.11.017, 2018.

McCune, B. and Keon, D.: Equations for potential annual direct incident radiation and heat load, J. Veg. Sci., 13, 603-606, https://doi.org/10.1111/j.1654-1103.2002.tb02087.x, 2002.

Meijer, C., Grootes, M. W., Koma, Z., Dzigan, Y., Gonçalves, R., Andela, B., van den Oord, G., Ranguelova, E., Renaud, N., and Kissling, W. D.: Laserchicken - A tool for distributed feature cal- 
culation from massive LiDAR point cloud datasets, SoftwareX, 12, 100626, https://doi.org/10.1016/j.softx.2020.100626, 2020.

Moeslund, J. E., Arge, L., Bøcher, P. K., Dalgaard, T., Odgaard, M. V., Nygaard, B., and Svenning, J.-C.: Topographically controlled soil moisture is the primary driver of local vegetation patterns across a lowland region, Ecosphere, 4, art91, https://doi.org/10.1890/ES13-00134.1, 2013.

Moeslund, J. E., Zlinszky, A., Ejrnæs, R., Brunbjerg, A. K., Bøcher, P. K., Svenning, J.-C., and Normand, S.: Light detection and ranging explains diversity of plants, fungi, lichens, and bryophytes across multiple habitats and large geographic extent, Ecol. Appl., 29, e01907, https://doi.org/10.1002/eap.1907, 2019.

Montgomery, J., Brisco, B., Chasmer, L., Devito, K., Cobbaert, D., and Hopkinson, C.: SAR and Lidar Temporal Data Fusion Approaches to Boreal Wetland Ecosystem Monitoring, Remote Sens.-Basel, 11, 161, https://doi.org/10.3390/rs11020161, 2019.

Moore, I. D., Grayson, R. B., and Ladson, A. R.: Digital terrain modelling: A review of hydrological, geomorphological, and biological applications, Hydrol. Process., 5, 3-30, https://doi.org/10.1002/hyp.3360050103, 1991.

Morgan-Wall, T.: rayshader: Create Maps and Visualize Data in 2D and 3D, https://www.rayshader.com (last access: 10 February 2022), 2020.

Moudrý, V., Lecours, V., Malavasi, M., Misiuk, B., Gábor, L., Gdulová, K., Šímová, P., and Wild, J.: Potential pitfalls in rescaling digital terrain model-derived attributes for ecological studies, Ecol. Inf., 54, 100987, https://doi.org/10.1016/j.ecoinf.2019.100987, 2019.

Moudrý, V., Klápště, P., Fogl, M., Gdulová, K., Barták, V., and Urban, R.: Assessment of LiDAR ground filtering algorithms for determining ground surface of non-natural terrain overgrown with forest and steppe vegetation, Measurement, 150, 107047, https://doi.org/10.1016/j.measurement.2019.107047, 2020.

Nord-Larsen, T., Riis-Nielsen, T., and Ottosen, M. B.: Forest resource map of Denmark: Mapping of Danish forest resource using ALS from 2014-2015, Department of Geosciences and Natural Resource Management, University of Copenhagen, Copenhagen, Denmark, https://static-curis.ku.dk/portal/ files/177147904/LiDAR2014_report.pdf (last access: 10 February 2022), 2017.

Pazúr, R., Huber, N., Weber, D., Ginzler, C., and Price, B.: A national extent map of cropland and grassland for Switzerland based on Sentinel-2 data, Earth Syst. Sci. Data Discuss. [preprint], https://doi.org/10.5194/essd-2021-60, in review, 2021

Pekel, J.-F., Cottam, A., Gorelick, N., and Belward, A. S.: Highresolution mapping of global surface water and its long-term changes, 540, 418-422, https://doi.org/10.1038/nature20584, 2016.

Peura, M., Silveyra Gonzalez, R., Müller, J., Heurich, M., Vierling, L. A., Mönkkönen, M., and Bässler, C.: Mapping a 'cryptic kingdom': Performance of lidar derived environmental variables in modelling the occurrence of forest fungi, Remote Sens. Environ., 186, 428-438, https://doi.org/10.1016/j.rse.2016.09.003, 2016.

Pfeifer, N., Mandlburger, G., Otepka, J., and Karel, W.: OPALS - A framework for Airborne Laser Scanning data analysis, Comput Environ Urban, 45, 125-136, https://doi.org/10.1016/j.compenvurbsys.2013.11.002, 2014.
Quinn, P., Beven, K., Chevallier, P., and Planchon, O.: The prediction of hillslope flow paths for distributed hydrological modelling using digital terrain models, Hydrol. Process., 5, 59-79, https://doi.org/10.1002/hyp.3360050106, 1991.

Reback, J., McKinney, W., den Bossche, J. V., jbrockmendel, Augspurger, T., Cloud, P., gfyoung, Sinhrks, Klein, A., Tratner, J., She, C., Roeschke, M., Petersen, T., Ayd, W., Hayden, A., Hawkins, S., Schendel, J., Garcia, M., Jancauskas, V., Battiston, P., Seabold, S., chris-b1, h-vetinari, Hoyer, S., Overmeire, W., Mehyar, M., nouri, behzad, Kluyver, T., Whelan, C., and Chen, K. W.: pandas-dev/pandas: v0.24.2, Zenodo, https://doi.org/10.5281/zenodo.3509135, 2019.

Roussel, J.-R., Auty, D., Coops, N. C., Tompalski, P., Goodbody, T. R. H., Meador, A. S., Bourdon, J.-F., de Boissieu, F., and Achim, A.: lidR: An R package for analysis of Airborne Laser Scanning (ALS) data, Remote Sens. Environ., 251, 112061, https://doi.org/10.1016/j.rse.2020.112061, 2020.

SAGA-GIS Tool Library Documentation v7.8.2: http: //www.saga-gis.org/saga_tool_doc/7.8.2/index.html, last access: 28 June 2021.

Senf, C., Pflugmacher, D., Hostert, P., and Seidl, R.: Using Landsat time series for characterizing forest disturbance dynamics in the coupled human and natural systems of Central Europe, ISPRS J. Photogramm., 130, 453-463, https://doi.org/10.1016/j.isprsjprs.2017.07.004, 2017.

Sithole, G. and Vosselman, G.: Experimental comparison of filter algorithms for bare-Earth extraction from airborne laser scanning point clouds, ISPRS J. Photogramm., 59, 85-101, https://doi.org/10.1016/j.isprsjprs.2004.05.004, 2004.

Thers, H., Brunbjerg, A. K., Læssøe, T., Ejrnæs, R., Bøcher, P. K., and Svenning, J.-C.: Lidar-derived variables as a proxy for fungal species richness and composition in temperate Northern Europe, Remote Sens. Environ., 200, 102-113, https://doi.org/10.1016/j.rse.2017.08.011, 2017.

Tweedy, P. J., Moriarty, K. M., Bailey, J. D., and Epps, C. W.: Using fine scale resolution vegetation data from LiDAR and ground-based sampling to predict Pacific marten resting habitat at multiple spatial scales, Forest Ecol. Manag., 452, 117556, https://doi.org/10.1016/j.foreco.2019.117556, 2019.

Valbuena, R., O'Connor, B., Zellweger, F., Simonson, W., Vihervaara, P., Maltamo, M., Silva, C. A., Almeida, D. R. A., Danks, F., Morsdorf, F., Chirici, G., Lucas, R., Coomes, D. A., and Coops, N. C.: Standardizing Ecosystem Morphological Traits from 3D Information Sources, Trends Ecol. Evol., 35, S0169534720300811, https://doi.org/10.1016/j.tree.2020.03.006, 2020.

Van Rossum, G. and Drake Jr., F. L.: Python reference manual, Centrum voor Wiskunde en Informatica Amsterdam, https://ir.cwi.nl/ pub/5008 (last access: 10 February 2022), 1995.

Vierling, K. T., Vierling, L. A., Gould, W. A., Martinuzzi, S., and Clawges, R. M.: Lidar: shedding new light on habitat characterization and modeling, Front Ecol. Environ., 6, 90-98, https://doi.org/10.1890/070001, 2008.

Vo, A.-V., Laefer, D. F., and Bertolotto, M.: Airborne laser scanning data storage and indexing: state-ofthe-art review, Int. J. Remote. Sens., 37, 6187-6204, https://doi.org/10.1080/01431161.2016.1256511, 2016.

Wagner, W., Ullrich, A., Ducic, V., Melzer, T., and Studnicka, N.: Gaussian decomposition and calibration 
of a novel small-footprint full-waveform digitising airborne laser scanner, ISPRS J. Photogramm., 60, 100-112, https://doi.org/10.1016/j.isprsjprs.2005.12.001, 2006.

Wang, L. and Liu, H.: An efficient method for identifying and filling surface depressions in digital elevation models for hydrologic analysis and modelling, Int. J. Geogr. Inf. Sci., 20, 193213, https://doi.org/10.1080/13658810500433453, 2006.

Weiss, A.: Topographic position and landforms analysis, Poster presentation, ESRI user conference, 9-13 July 2001, San Diego, CA, http://www.jennessent.com/downloads/TPI-poster-TNC_ 18x22.pdf (last access: 21 February 2022), 2001.

$\mathrm{Xu}, \mathrm{C}$., Manley, B., and Morgenroth, J.: Evaluation of modelling approaches in predicting forest volume and stand age for small-scale plantation forests in New Zealand with RapidEye and LiDAR, Int. J. Appl. Earth Obs., 73, 386-396, https://doi.org/10.1016/j.jag.2018.06.021, 2018.
Yokoyama, R.: Visualizing Topography by Openness: A New Application of Image Processing to Digital Elevation Models, Photogramm. Eng. Rem. S., 68, 257-265, 2002.

Zellweger, F., Baltensweiler, A., Ginzler, C., Roth, T., Braunisch, V., Bugmann, H., and Bollmann, K.: Environmental predictors of species richness in forest landscapes: abiotic factors versus vegetation structure, J. Biogeogr., 43, 1080-1090, https://doi.org/10.1111/jbi.12696, 2016. 